\title{
Modelling and experimental analysis of low concentrating solar panels for use in building integrated and applied photovoltaic (BIPV/ BAPV) systems
}

\author{
Homan Hadavinia, Harjit Singh* \\ College of Engineering, Design and Physical Sciences, Brunel University, London, UK
}

\section{A R T I C L E I N F O}

\section{Article history:}

Received 29 September 2018

Received in revised form 13 January 2019

Accepted 22 February 2019

Available online 27 February 2019

\section{Keywords:}

Ray tracing

Compound parabolic concentrator

V-trough concentrator

Concentrating photovoltaics

BIPV

BAPV

\begin{abstract}
A B S T R A C T
Geometrically equivalent V-trough and compound parabolic concentrators (CPC) were simulated to characterise the variation in optical efficiency using ray tracing modelling with COMSOL Multiphysics. The effect of CPC truncation and V-trough side wall angles were studied. The truncated CPC demonstrated much improved light acceptance outside the designed angle of acceptance when compared to the original CPC design and V-trough-like characteristics past the original design acceptance angles, consequently reducing material consumption for the manufacture of truncated CPC and therefore reduction in the cost of the system. Truncated CPCs showed optical efficiency equal to their full height counterparts, but a lower concentration ratio ( 4 at full, 3.6 at half and 2.7 at $50 \mathrm{~mm}$ height) due to an equivalent reduction of the inlet aperture size. The $\mathrm{V}$-trough had a higher optical concentration ratio over $15-30^{\circ}$ angle of incidents (AoI), with the CPC taking over from $30^{\circ}$ AoI upwards. Experiments were performed on a $50 \mathrm{~mm}$ truncated CPC and a $22^{\circ}$ Trough Wall Angle (TWA) V-trough collector under outdoor conditions. Experimentally measured data showed good correlation with ray tracing simulation results. Both experimental and the ray tracing analyses showed the CPC concentrator achieving a $2.4 \%$ higher power output compared to the V-trough design.
\end{abstract}

(c) 2019 Elsevier Ltd. All rights reserved.

\section{Introduction}

From the total renewable power generation capacity of 1081 GWp (not including hydro) in 2017 [1], solar photovoltaic (PV) accounted for approximately $402 \mathrm{GWp}(37.2 \%)$ and concentrating solar thermal power technologies about $4.9 \mathrm{GWp}$. Concentrating Photovoltaic (CPV) technology has entered the market as a utility scale option for the generation of electricity with more than 370 MWp in cumulative installations, including several sites with larger than $30 \mathrm{MWp}$ installed capacity [2]. The top highest electricity production capacity is at Golmud 1 plant (57.96 MWp) and Golmud 2 plant (79.83 MWp) in the Qinghai province (China) and Touwsrivier project (Western Cape, South Africa) at a capacity of 44.19 MWp. A key advantage of a CPV system is its higher conversion and optical efficiency. For a given peak power rating, a CPV system requires less land area than other photovoltaic technologies. Fresnel

\footnotetext{
* Corresponding author.

E-mail addresses: Homan.Hadavinia@brunel.ac.uk (H. Hadavinia), Harjit.Singh@ brunel.ac.uk (H. Singh).
}

and other lens-based imaging optical concentrators account for majority of the CPV installations worldwide. Most of the CPVs actively track the Sun in order to achieve meaningful concentration throughout the day. However, an active solar tracking mechanism adds to the capital and operating and maintenance costs while consuming a certain fraction of the generated power [3]. Therefore, nonimaging and stationary techniques of concentrating solar radiation are more effective, especially for installation on buildings. Application of the nonimaging optics can deliver moderate level of concentration $(<10)$ with stationary concentrators requiring no maintenance of moving parts such as sun-tracking mechanisms, making them most suitable for buildings.

The key principle of CPV is the use of cost-effective concentrating optics that reduces the PV cell area, offsetting the high cost multi-junction solar cells made from heavily mined and relatively rare metals with relatively cheap optical systems, enabling the achievement of a levelized cost of electricity (LCOE) competitive with standard flat-plate PV technology [2,4]. The theoretical limit associated with solar-to-electricity conversion with an infinite number of junctions have a limiting efficiency of $86.8 \%$ under highly concentrated sunlight [5-7] while lab examples of multi-junction 
cells have demonstrated performance over $46 \%$ under concentrated sunlight [8].

Many researchers have used ray-tracing technique for theoretical characterisation of a concentrating system for PV applications $[9,10]$ while others used experimental optical efficiency and solar energy flux distribution by various methods [10-12]. Al-Shohani et al. [13] used OptisWorks ray tracing software to determine the optimum design of the V-trough concentrator. Sangani and Solanki [14] reported a 2-sun V-trough concentrator, which showed a $44 \%$ increased electrical output leading to a $24 \%$ overall reduction in cost of electricity. Mallick et al. $[15,16]$ studied a 2 -sun CPC leading to a $62 \%$ yield increase.

Building Integrated Photovoltaics (BIPV) are PV systems integrated into building elements such as roofs and building facades or the building materials themselves [17]. In contrast Building Applied Photovoltaics (BAPV) are applied over traditional elements of a building, usually applied post-construction rather than during the original building construction [18,19]. The cost of a BIPV system can be lowered by reducing PV module and component manufacturing costs, operation and maintenance costs and improving PV and other component efficiencies [20].

In this research, two geometrically equivalent non-imaging $\mathrm{V}$ trough and CPC concentrators are investigated, using COMSOL Multiphysics computational tool and experimentally, with a target of increasing the efficiency of solar cells employed in BIPVs. Several concentrator geometries and configurations are studied at the relevant angles of incidence (AoI) of the incoming solar radiation. For CPC, three configurations are presented based on a 4concentration ratio system. In addition, the effects of truncation of CPC reflector walls and V-trough Trough Wall Angle (TWA) are also investigated. The results of ray tracing analysis are used for designing and manufacturing of a CPC and a V-trough systems and outdoor experiments have been carried out on these systems to understand their optical and energy conversion characteristics. Finally, the results of ray tracing analysis are compared with the experimental results.

\section{Geometries of V-trough and CPC concentrators}

V-trough concentrators made from linearly inclined reflectors to concentrate light from a wider inlet aperture to a narrower absorber area (Fig. 1).

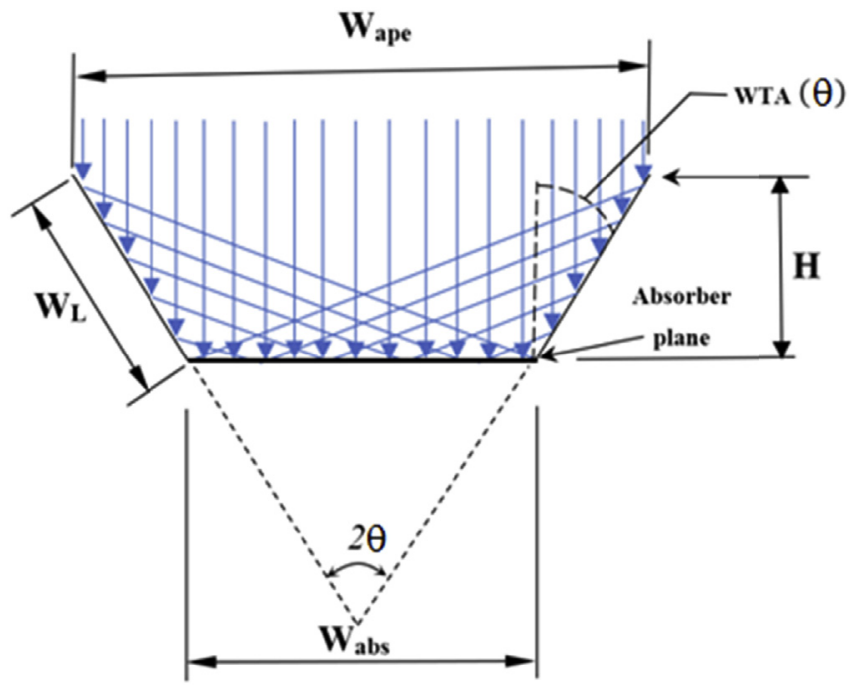

Fig. 1. Schematic of a V-trough concentrator cross-section.
The CPC is so called due to the inclusion of two parabolic reflectors in the system. It is designed such that the focal point of one parabola is the base of the opposing one. Fig. 2 shows the CPC comprised of two parabolas, $P Q$ with focal point $Q^{\prime}$, and $P^{\prime} Q^{\prime}$ with focal point $Q$. These parabolas are rotated by the acceptance half angle $\theta_{h}$, with focal length $f$ from the vertex of the parabola (A) to its focus (Q). CPC is considered the best static concentrator for solar radiation collection due to high optical efficiency and the capability to collect both diffuse and direct radiations [21,22]. Simultaneous work was done on CPCs by Hinterberger \& Winston in 1966 [6,23] and Baranov [24] and Baranov and Melnikov [25] in 1965 and 1966, respectively. This led to a publication on the suggestion of 3D CPC (termed as Parabolotoroidal mirrors) in 1966 by Baranov [26]. Finally, in 1974 the 2D CPC geometry was described by Winston [27]. A comprehensive and up-to-date review of CPC design principles for miscellaneous configurations, applications, performance

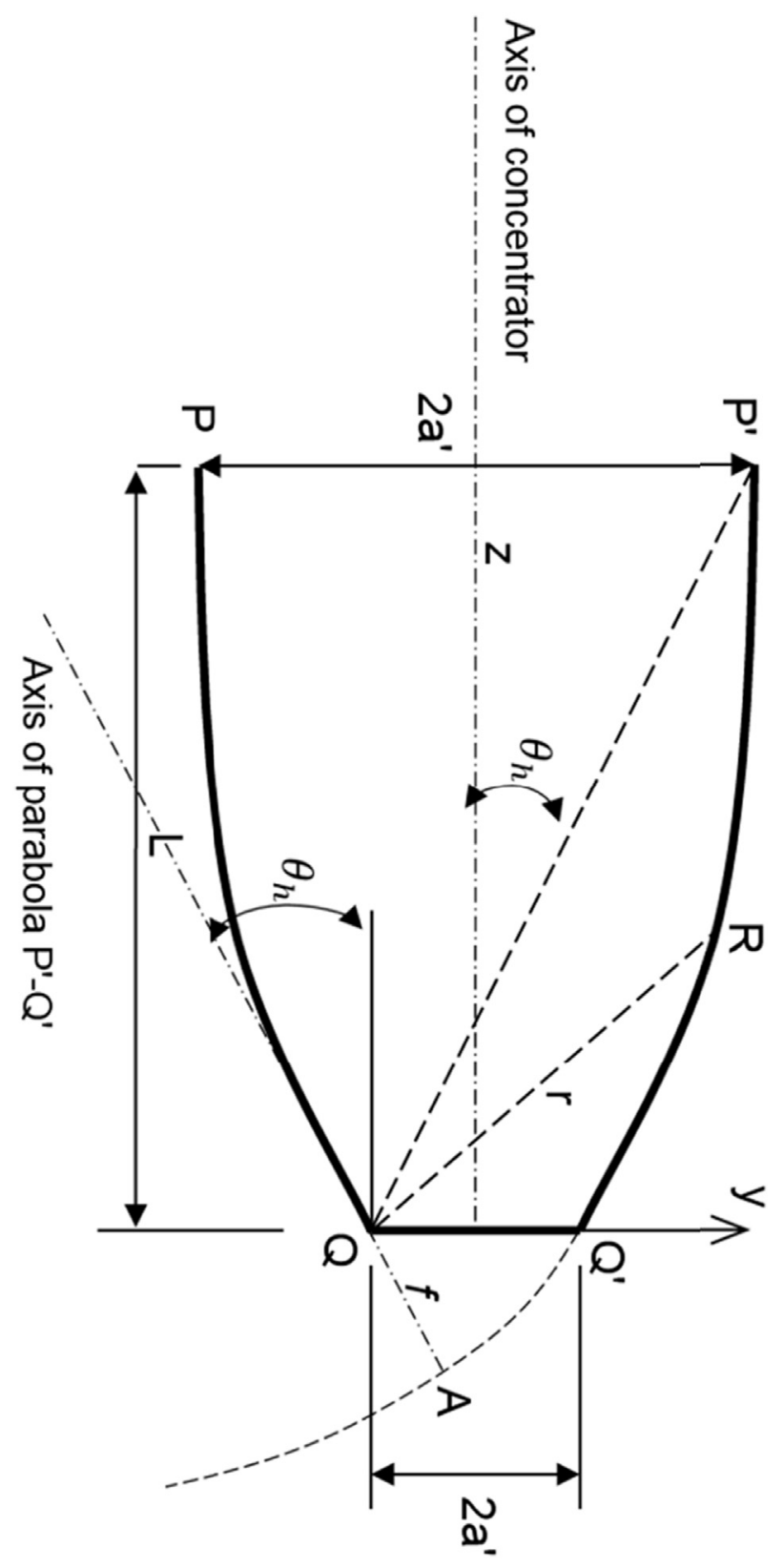

Fig. 2. Schematic of a CPC cross-section. 
predictions and technological advances are presented in Ref. [28].

\section{Ray trace modelling}

In ray trace modelling hundreds or thousands of different rays are simulated and optical physics are used to predict how each ray interacts at each surface in the model domain. In this research, ray trace modelling is used to investigate the performance of full height and truncated CPC and V-trough concentrators. From these analyses, the power output of each design is calculated, the distribution of light on the solar cell is considered and the results are verified with the experimental measurements.

\subsection{Parametric driven geometry}

The number of simulations required to model every design over the wide array of conditions is prohibitively large. For the V-trough, modelling AoI of $0-45^{\circ}$ and TWA of $0-45^{\circ}$, a total of $46 \times 46$ $(=2116)$ simulations are required. This is assuming only symmetrical V-trough is to be considered. If asymmetrical V-troughs (those with left and right reflector sides having different lengths) are modelled then the total simulations required would grow exponentially. The same principle applies to CPC concentrators; every CPC design and every truncation level needs to be modelled for every Aol.

A novel approach was used to convert the geometries in both 2D and 3D from manual CAD drawings to parametrically driven geometries. The aim once completed is that the solver (COMSOL Multiphysics) is given a range of various parameters and is able to automatically create and update the geometries and boundary conditions, allowing significant numbers of simulations to run automated.

\subsubsection{V-trough concentrator}

For the purpose of modelling, four parameters, inlet light, TWA $(\theta)$, wall length ( $W_{L}$-Fig. 1$)$ and wall length horizontal component $\left(W_{x}\right)$, were defined as described in Eqs. (1) and (2) assuming the acceptable height for BIPV application is $\mathrm{H}=50 \mathrm{~mm}$.

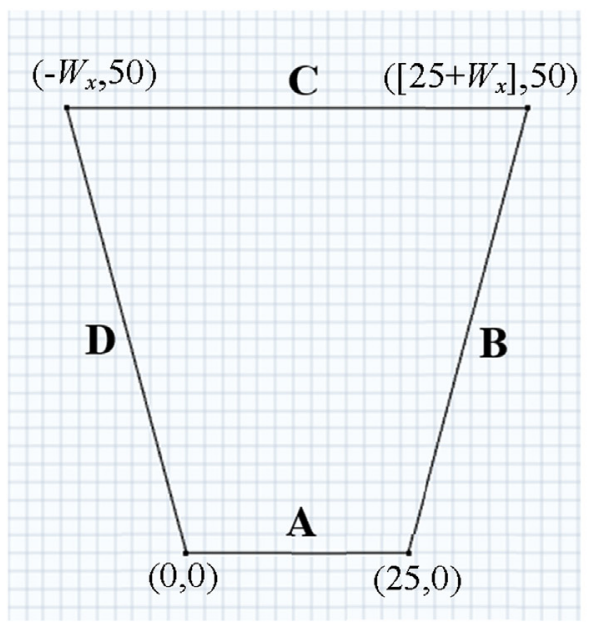

(a) V-trough parameter schema
$W_{L}=\frac{50}{\cos (\theta)}$

$W_{x}=W_{L} \sin (\theta)$

The V-trough was then implemented in COMSOL Multiphysics as a Bezier polygon consisting of the components shown in Fig. 3(a) and described as follows.

A. $(0,0)$ to $(25,0)$ representing the $25 \mathrm{~mm}$ wide horizontally aligned solar PV cell receiver

B. $(25,0)$ to $\left(25+W_{x}, 50\right)$ representing the right-side wall of the $V$ trough

C. $\left(25+W_{x}, 50\right)$ to $\left(-W_{x}, 50\right)$ going back twice the horizontal component of the reflectors as well as $25 \mathrm{~mm}$ receiver

D. $\left(-W_{x}, 50\right)$ to $(0,0)$ reaching the left-most side of the solar receiver

\subsubsection{CPC concentrator}

The geometry of the $\mathrm{CPC}$, Fig. 3(b), requires the rotation of the parabolas by the acceptance half angle, as such the equation of the parabola is changed. Absolute values for the $50 \mathrm{~mm}$ CPC design selected are provided in parenthesis, derived from the equations below.

A rotation matrix derived from the Euler Formula in two dimensions takes the form:

$R_{\theta}=\left[\begin{array}{cc}\cos \theta & -\sin \theta \\ \sin \theta & \cos \theta\end{array}\right]$

This is used to get the new $x$ and $y$ coordinates (denoted as $x^{\prime}$ and $\left.y^{\prime}\right)$ by multiplication with the column vector:

$v^{\prime}=R_{\theta} v_{0}$

Furthermore, once a function is rotated, the result need not be a function i.e. a function has one $y$-point for every $x$-point, once rotated, it is possible an $x$ value has more than one $y$ value. As such, the parabola will take a parametric form; rather than $x \rightarrow y(x)$, the parabola will be described in the form $s \rightarrow(x(s), y(s))$.

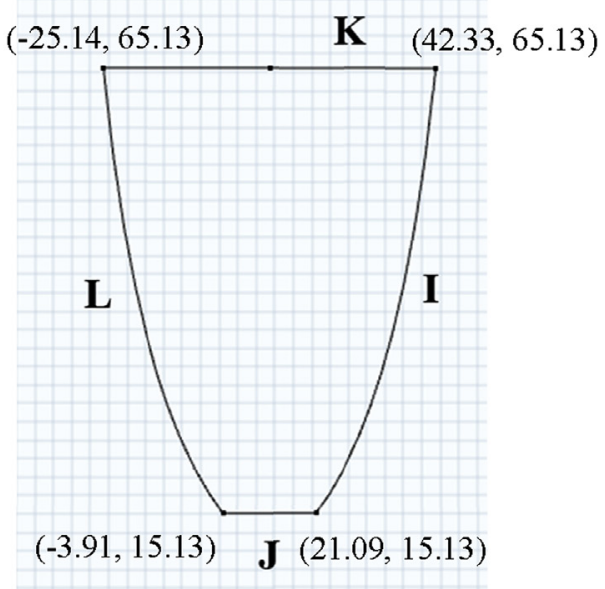

(b) CPC parameter schema

Fig. 3. Annotated (a) V-trough and (b) CPC schematics in COMSOL Multiphysics Geometry. 
The parametric form of the rotated parabola is derived by:

$\left[\begin{array}{l}x^{\prime} \\ y^{\prime}\end{array}\right]=\left[\begin{array}{cc}\cos \theta & -\sin \theta \\ \sin \theta & \cos \theta\end{array}\right]\left[\begin{array}{l}x \\ y\end{array}\right]$

This leads to b $\left(-f \sin \theta_{h}, f \cos \left(\theta_{h}\right)\right)$ to $\left(-f \sin \left(\theta_{h}\right)+W_{a b s}, f \cos \left(\theta_{h}\right)\right)$

$c\left(-f \sin \left(\theta_{h}\right)+W_{a b s}, f \cos \left(\theta_{h}\right)\right)$ to $\left(-2 f \sin \left(\theta_{h}\right)+W_{a b s}, 0\right)$

$K$. Inlet half-aperture set up as a 1-step Bezier Polygon:

$a\left(-f \sin \left(\theta_{h}\right)+\frac{W_{a b s}}{2}, \sin \left(-\theta_{h}\right) \cdot\left(-\right.\right.$ top $\left.\left._{\text {root }}\right)+\cos \left(-\theta_{h}\right) \cdot \frac{\left(- \text { top }_{\text {root }}\right)^{2}}{4 f}\right)$

to

$\left(\cos \left(\theta_{h}\right)\right.$ top $_{\text {root }}-\sin \left(\theta_{h}\right) \frac{\text { top }_{\text {root }}^{2}}{4 f}, \sin \left(\theta_{h}\right)$ top root $\left.+\cos \left(\theta_{h}\right) \frac{\text { top }_{\text {root }}^{2}}{4 f}\right)$

$x^{\prime}=x \cdot \cos (\theta)-y \cdot \sin (\theta)$

$y^{\prime}=x \cdot \sin (\theta)+y \cdot \cos (\theta)$

Automating the truncation of the CPCs was achieved by creating a parametric curve within COMSOL Multiphysics with a minimum and maximum plot value. The maximum value represented the height of the truncated CPC for that simulation instance and the minimum the base (solar cell absorber width) of the CPC.

The maximum value was calculated by finding the root of the $y^{\prime}$ expression and substituting $y_{\text {top }}$ for $y^{\prime}$ :

$y_{\text {top }}=s \cdot \sin \theta+\frac{s^{2}}{4 f} \cdot \cos \theta$

The above quadratic equation was solved using the quadratic equation:

$\frac{s^{2}}{4 f} \cos \theta+s \cdot \sin \theta-y_{\text {top }}=0$

$s=\frac{-\sin \theta \pm \sqrt{\sin ^{2} \theta+\frac{y_{\text {top }} \cos \theta}{f}}}{\cos \theta / 2 f}$

The lower bound of the parametric curve was determined by the focal length of the CPC. This was the $y$-value of the rotated parabola which formed the base of the CPC. The process was applied again to find the cut-off point of the lower parabolas.

The symmetric CPC was then defined as a set of geometries as follows in sections I-L below:

I. First parabola set up as a Parametric curve drawn to top root: $_{\text {: }}$

$a \quad x=\cos \left(\theta_{h}\right) s-\sin \left(\theta_{h}\right) \frac{s^{2}}{4 f}$

b $y=\sin \left(\theta_{h}\right) s-\cos \left(\theta_{h}\right) \frac{s^{2}}{4 f}$

Where $f$ is the focal length of CPC parabolas and $\theta_{h}$ the CPC half acceptance angle.

J. Focal lines and absorber aperture set up as a Bezier polygon with segments:

a $(0,0)$ to $\left(-f \sin \theta_{h}, f \cos \theta_{h}\right)$
Where $W_{a b s}$ is the absorber width (PV cell width), set as $25 \mathrm{~mm}$ for the study.

L. For the symmetric CPC, the mirror transformation feature was used to get the opposing parabola and inlet aperture. In the case of non-symmetric CPC, a second parametric curve going to top root was defined as:

$a \quad x=\cos \left(-\theta_{h}\right) s-\sin \left(-\theta_{h}\right) \frac{s^{2}}{4 f}$

b $y=\sin \left(-\theta_{h}\right) s+\cos \left(-\theta_{h}\right) \frac{s^{2}}{4 f}$

Once set up, COMSOL Multiphysics can change the geometry and boundary conditions through a set of four core parameters: AoI angle $_{\text {light }}$, CPC concentration ratio $C_{r}$, PV cell width $W_{a b s}$ and truncation level (\%). A 'parametric sweep' was used to run groups of simulations with COMSOL Multiphysics given ranges of each parameter to sweep.

\subsection{Compound parabolic concentrator (CPC)}

A symmetric CPC with concentration ratio of $4\left(C_{r}=4\right)$ and $25 \mathrm{~mm}$ wide absorber surface was considered. The geometric features of the concentrator are as follows:

- Half Acceptance angle: $\theta_{h}=\sin ^{-1}\left(\frac{1}{4}\right)=14.478^{\circ}$

- Height of CPC: $\frac{w_{a b s}+w_{a p}}{2} * \cot \left(\theta_{h}\right)=242.06 \mathrm{~mm}$

The CPC was modified by truncating the height profile at three levels; see Table 1, in order to achieve a BIPV/BAPV capable geometry.

All designs underwent ray tracing simulation in COMSOL Multiphysics using Geometric Optics for a maximum of 3 ns of ray propagation time. The concentrators were simulated under Aol ranging from $0^{\circ}$ to $45^{\circ}$, see example results shown in Fig. 4 . As the

Table 1

CPC design parameters.

\begin{tabular}{lllll}
\hline CPC & Cr & Height $(\mathrm{mm})$ & Height $(\%)$ & $\mathrm{Cr}(\%)$ \\
\hline Full & 4 & 242.06 & $100 \%$ & $100 \%$ \\
Half & 3.6 & 121.03 & $50 \%$ & $90 \%$ \\
$50 \mathrm{~mm}$ & 2.7 & 50 & $20.7 \%$ & $67.5 \%$ \\
\hline
\end{tabular}


AoI Full height
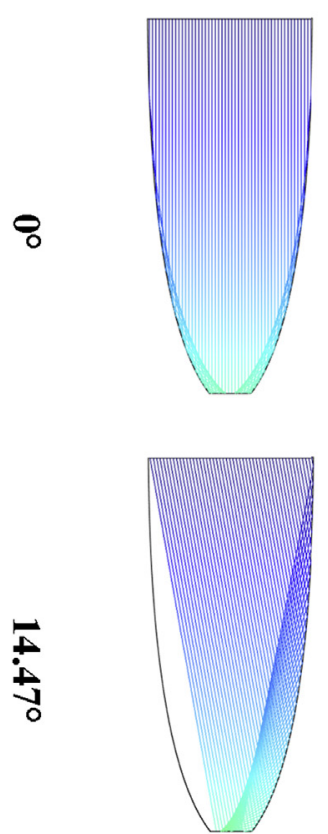

ज़
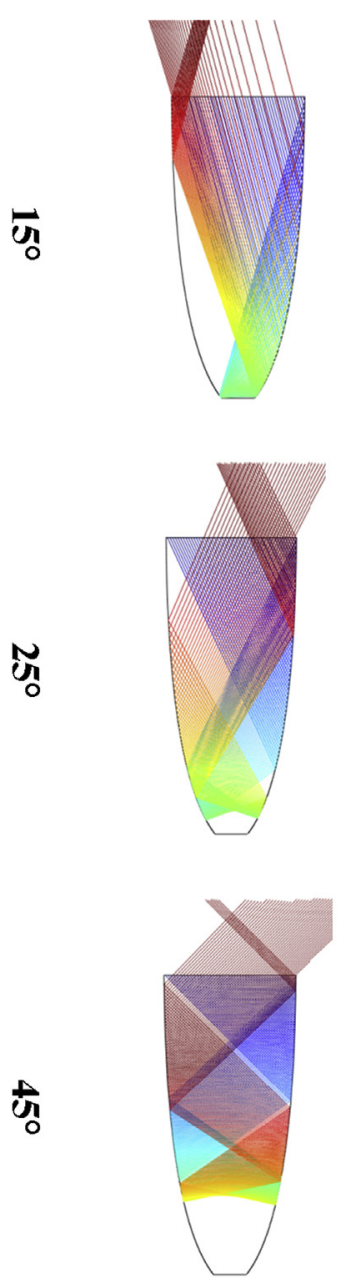

Half height
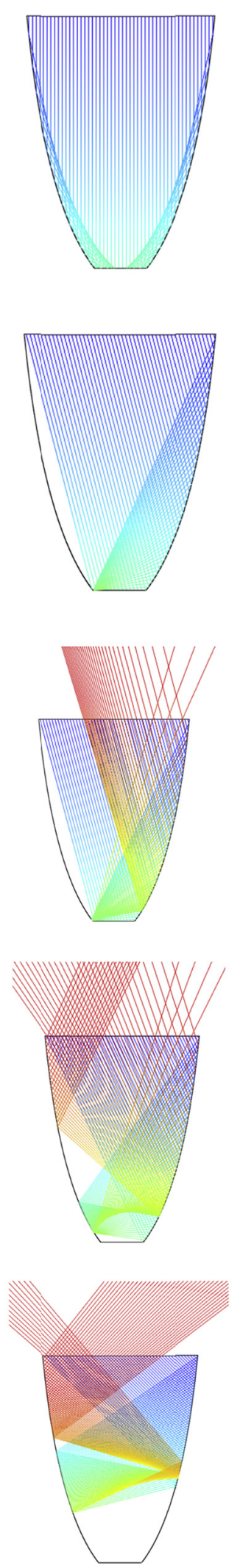

$50 \mathrm{~mm}$ height
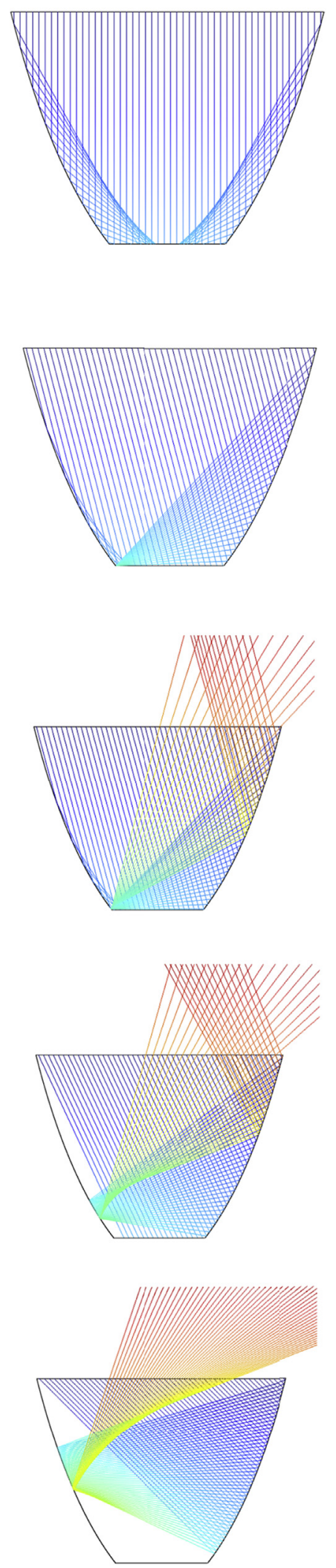

Fig. 4. Ray trace graphs of Full, Half and $50 \mathrm{~mm}$ height CPCs at a range of Aol. 
CPC concentrators considered were symmetrical, this applies to either direction giving a $90^{\circ}$ range for AoI, $45^{\circ}$ from either direction.

In order to evaluate the accuracy of the model and compare with theoretical data, the AoI is divided into 10 discrete divisions, in step of $0.1^{\circ}$ angular expanse, from $14^{\circ}$ to $15^{\circ}$. Subsequently, the AoI was further divided into a hundredth of one degree between $14.47^{\circ}$ and $14.48^{\circ}$ to pin point the exact angle at which the design acceptance half angle is surpassed. In total, 64 different Aol were considered for each CPC design.

As expected, up to the CPC design half acceptance angle of $14.47^{\circ}$ all rays were accepted - that is, the rays hit the absorber plane housing the solar cells. Within this $29^{\circ}$ range $\left( \pm 14.5^{\circ}\right)$, a $50 \%$ truncation of the reflector height resulted in only a $10 \%$ loss of concentration ratio and a reduction in the CPC height by $80 \%$ only reduced the concentration ratio by $1 / 3$ rd.

Beyond the half acceptance angle, the full height CPC showed a cliff-drop to zero output with all rays being reflected back out of the concentrator cavity. However, the truncated designs continued to partially accept sunlight with decreasing optical efficiency as the Aol increased. For example, the $50 \mathrm{~mm}$ height CPC continued to accept light up to AoI $=42^{\circ}$.

Another important measure of performance is the distribution of radiation intensity across the absorber plane; uneven distribution causes shading effects on the solar cells reducing their performance.

\subsection{V-trough concentrators}

The concentration ratio of the $\mathrm{V}$-trough concentrator was varied by changing TWA from $0^{\circ}$ to $45^{\circ}$. Furthermore, each design was simulated at AoI over the range of $0^{\circ}-45^{\circ}$ making a total of 2116 computing simulations. The results of the simulation are presented in Fig. 5.

Fig. 6 demonstrates why some V-trough geometries start at lower optical efficiency in Fig. 5, such as the one with TWA of $45^{\circ}$ starts at $20 \%$. At a TWA of $10^{\circ}$, the incident rays, which hit the reflector and eventually reach the absorber plane, land on the absorber at the same side as their corresponding reflector.

Ray acceptance should not constitute the final evaluation of a Vtrough design. In fact, the geometric concentration ratio $\left(C_{r}\right)$ is not constant on all designs; as the TWA increases, so does $C_{r}$. If only the data shown in Fig. 5 are considered, then a wrong conclusion could be drawn that the best $\mathrm{V}$-trough configuration is the one with TWA $=0^{\circ}$. However, the geometric concentration ratio of a $0^{\circ}$ TWA V-trough concentrator will remain unity even at $100 \%$ ray acceptance, i.e. it will be a non-concentrating geometry. On the other hand, the $25^{\circ}$ TWA V-trough had a $C_{r}$ of 2.87 , which though achieved an optical efficiency of $80 \%$ at $\mathrm{AoI}=0^{\circ}$ but is still significantly better than the $0^{\circ}$ TWA V-trough in terms of ray concentration achieved. Optical concentration ratio as used in this research is defined as:

$C_{\text {opt }}=\frac{\text { flux at receiver }}{\text { flux at aperture }}=C_{r} \cdot \eta$

where $\eta$ is the acceptance rate and $C_{r}$ is the geometric concentration ratio.

Fig. 7 and Fig. 8 respectively present the geometric

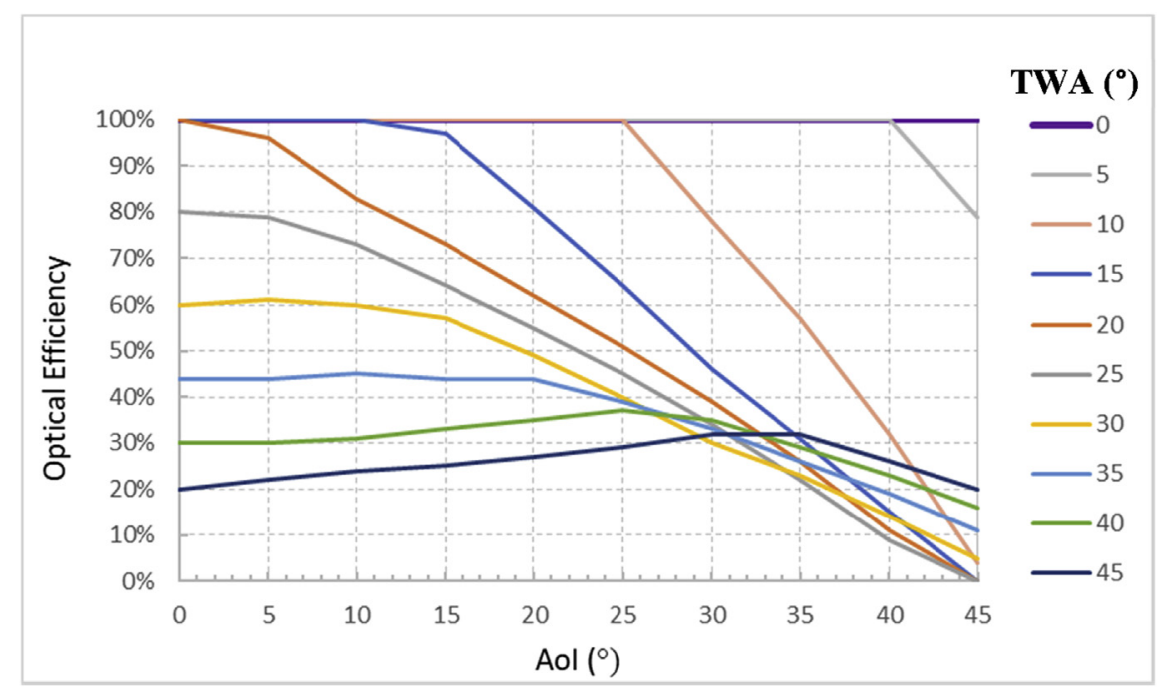

Fig. 5. The optical performance of V-trough configurations for various TWA and $0<\mathrm{AoI}<45^{\circ}$.

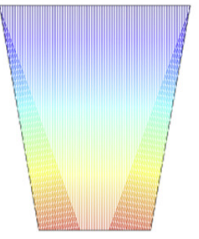

(a) $\mathrm{TWA}=10^{\circ}$
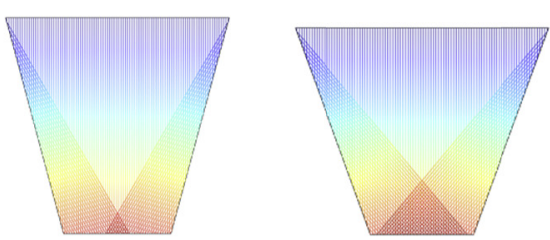

(b) $\mathrm{TWA}=15^{\circ}$

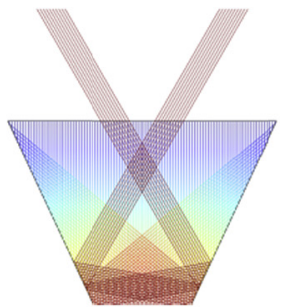

(d) $\mathrm{TWA}=25^{\circ}$

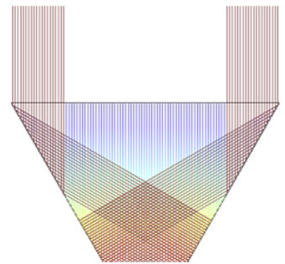

(e) $\mathrm{TWA}=30^{\circ}$

Fig. 6. Effect of varying TWA on the optical performance of $\mathrm{V}$-trough concentrators at $A o I=0^{\circ}$. 


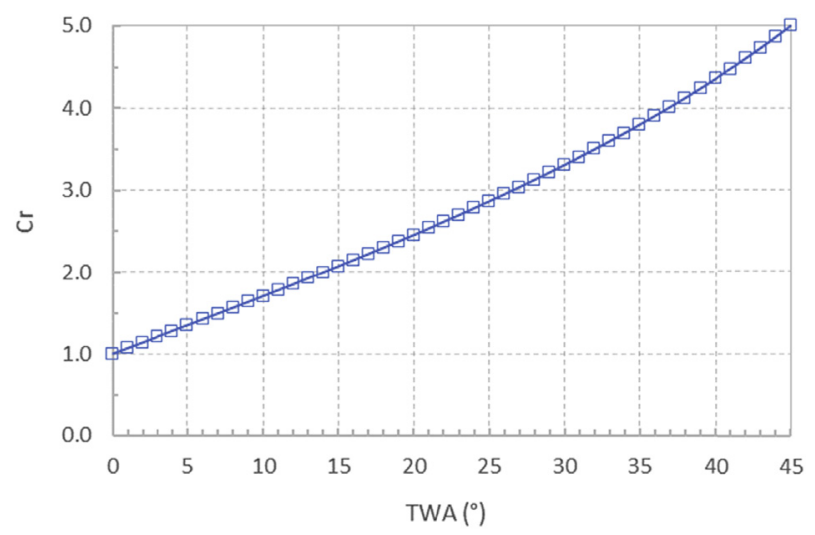

Fig. 7. Geometric concentration ratio of the V-trough geometries over the full range of $0<$ TWA $<45$.

concentration ratios and the optical efficiencies of V-trough concentrators for the full range of TWAs studied.
The best performance was found to depend on the peak solar irradiance period for the location at which the concentrator is to be installed. As this varies, so too does the Aol of interest to the employer of the system.

With the earth rotating $\sim 15^{\circ}$ /hour and assuming a 4 -h peak solar irradiance, the corresponding AoI would vary over $60^{\circ}$ equally distributed over the both sides of the peak solar irradiance time. To demonstrate the optical performance over this duration, results shown in Fig. 8 were filtered for Aol varying from $0^{\circ}$ to $30^{\circ}$ and the resulting optical concentration ratio obtained is shown in Fig. 9. Peak $C_{\text {opt }}$ is the best concentration ratio normally at $0^{\circ}$ AoI and Average $C_{\text {opt }}$ referring to the averaged $C_{\text {opt }}$ of the design over $0-30^{\circ}$.

This was followed by a deeper analysis with more rays and smaller TWA step of $1^{\circ}$ over a range of $15^{\circ}-25^{\circ}$, whilst AoI was varied from $0^{\circ}$ to $30^{\circ}$ at $20 \times$ resolution $\left(0.1^{\circ}\right.$ Aol steps). The summary of the results is shown in Fig. 10.

It can be seen in Fig. 10(b), the best design is the one with TWA of $22^{\circ}$ when considering average 4 -h performance $0-30^{\circ}$ Aol either direction for a $\mathrm{V}$-trough with these geometric features:

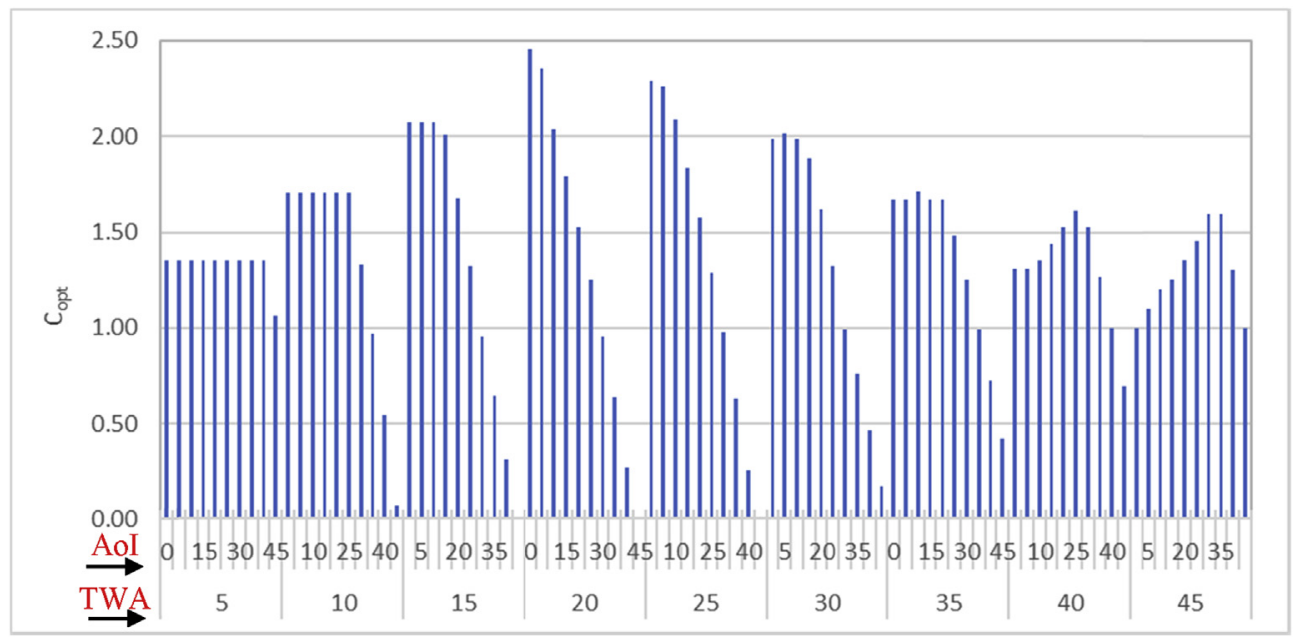

Fig. 8. Optical concentration ratio $\left(\mathrm{C}_{\mathrm{opt}}\right)$ of the V-trough concentrators for various TWAs (Major $\mathrm{x}$ axis) at different Aol (Minor $\mathrm{x}$ axis); angles are in $\left({ }^{\circ}\right)$.

\begin{tabular}{|c|c|}
\hline $\begin{array}{c}\text { V-trough } \\
\text { TWA }\end{array}$ & $\begin{array}{c}\text { Average } \\
\mathbf{C}_{\text {opt }}\end{array}$ \\
\hline $\mathbf{0}$ & 1.00 \\
$\mathbf{5}$ & 1.35 \\
$\mathbf{1 0}$ & 1.65 \\
$\mathbf{1 5}$ & 1.74 \\
$\mathbf{2 0}$ & 1.77 \\
$\mathbf{2 5}$ & 1.76 \\
$\mathbf{3 0}$ & 1.69 \\
$\mathbf{3 5}$ & 1.59 \\
$\mathbf{4 0}$ & 1.44 \\
$\mathbf{4 5}$ & 1.28 \\
\hline
\end{tabular}

(a)

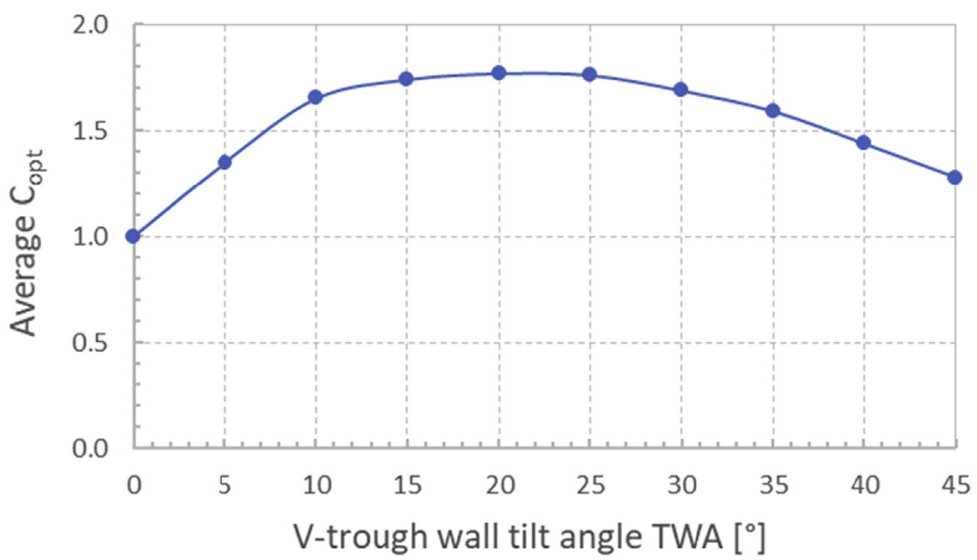

(b)

Fig. 9. Optical concentration ratio $\left(C_{o p t}\right)$ of V-trough concentrators at AoI range of $0^{\circ}$ to $30^{\circ}$ (a) numerically and (b) graphically. 


\begin{tabular}{|c|cc|}
\hline $\begin{array}{c}\text { V-trough } \\
\text { TWA }\end{array}$ & $\begin{array}{c}\text { Average } \\
\mathbf{C}_{\text {opt }}\end{array}$ & Peak $\mathrm{C}_{\text {opt }}$ \\
\hline $\mathbf{1 5}$ & 1.7748 & 2.0718 \\
$\mathbf{1 6}$ & 1.7751 & 2.1470 \\
$\mathbf{1 7}$ & 1.7763 & 2.2229 \\
$\mathbf{1 8}$ & 1.7780 & 2.2997 \\
$\mathbf{1 9}$ & 1.7801 & 2.3773 \\
$\mathbf{2 0}$ & 1.7827 & 2.4559 \\
$\mathbf{2 1}$ & 1.7851 & 2.5355 \\
$\mathbf{2 2}$ & 1.7855 & 2.5062 \\
$\mathbf{2 3}$ & 1.7851 & 2.4011 \\
\hline 24 & 1.7845 & 2.3387 \\
\hline 25 & 1.7813 & 2.2865 \\
\hline
\end{tabular}

(a)

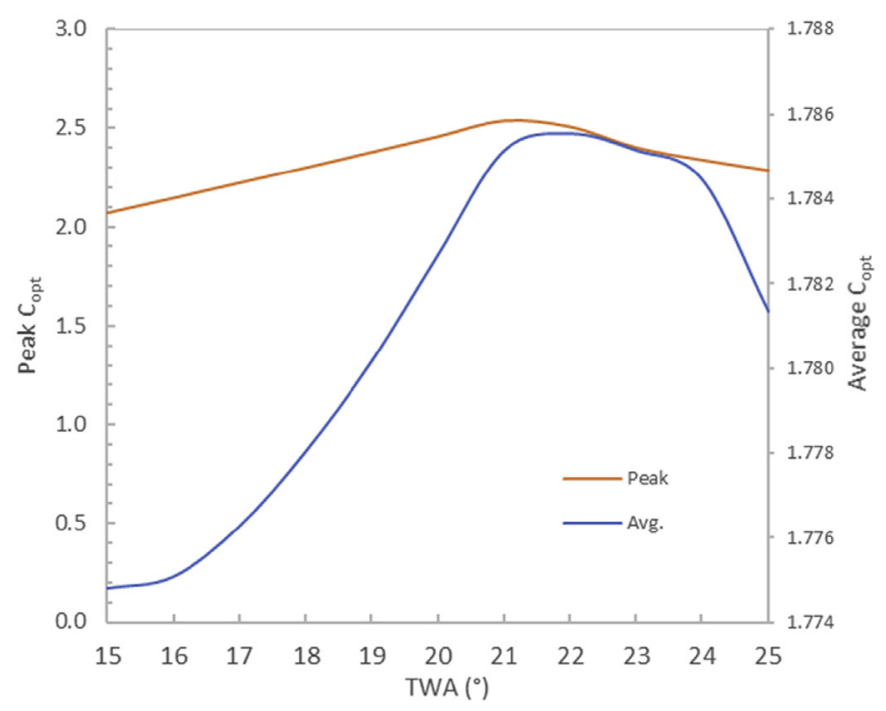

(b)

Fig. 10. High-resolution results for V-trough geometries (TWA $15-25^{\circ}$ ) for Aol varying from $0^{\circ}$ to $30^{\circ}$ in (a) tabular and (b) graphical format. Peak $C_{\text {opt }}$ refers to the V-trough's best performance typically at $0^{\circ} \mathrm{Aol}$, with Average. $\mathrm{C}_{\mathrm{opt}}$ referring to its average $\mathrm{C}_{\mathrm{opt}}$ over $0-30^{\circ} \mathrm{AoI}$.

- Height: $50 \mathrm{~mm}$

- Absorber width: $25 \mathrm{~mm}$; Aperture width: $65.4 \mathrm{~mm}$

- Geometric Concentration Ratio $C_{r}: 2.616$

- Optical Concentration Ratio $C_{\text {opt }}$ : Average: 1.786; Peak: 2.506

\subsection{Comparison of V-trough and CPC concentrators}

COMSOL Multiphysics ray tracing results for the performances of the CPCs and V-trough concentrators, in terms of $C_{o p t}$, as a function of the Aol are shown in Fig. 11. It can be seen all CPC variants had $100 \%$ acceptance to all incident rays till Aol equals the design half acceptance angle of $14.47^{\circ}$. The untruncated CPC showed a cliff-drop to zero acceptance beyond this angle. On the other hand, the $22^{\circ}$ TWA V-trough concentrator underwent a steady linear decline reaching zero acceptance at AoI $\approx 43^{\circ}$.

Truncation expectedly caused a significant improvement in the optical performance of CPC collectors outside of their $14.47^{\circ}$ angle

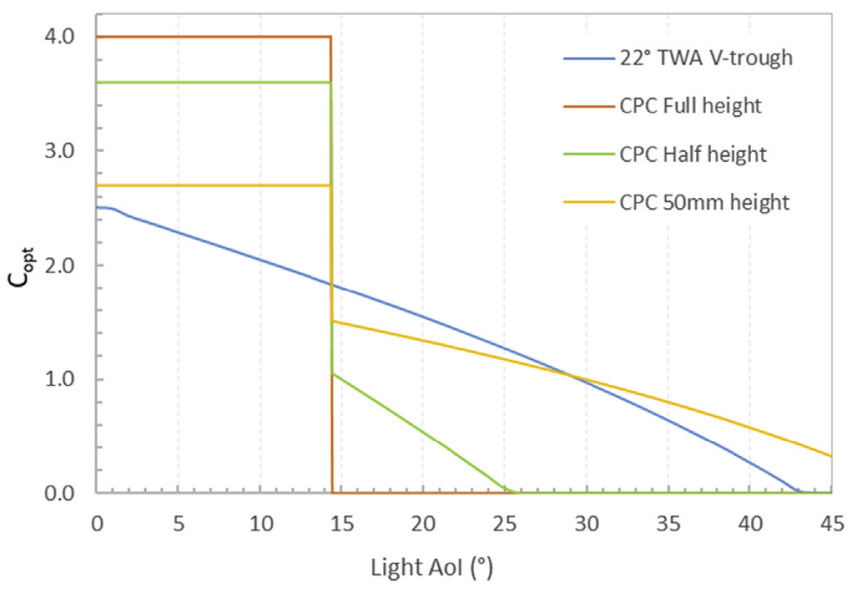

Fig. 11. $\mathrm{C}_{\mathrm{opt}}$ of $\mathrm{V}$-trough and $\mathrm{CPC}$ concentrators at various truncation levels. of acceptance. All CPC showed a sudden drop in the performance for Aol greater than half acceptance angle, however, the truncated designs exhibited gradual decline in their performance of varying slopes rather than a cliff-drop in the acceptance. In fact, the halftruncated and $50 \mathrm{~mm}$ height CPC began to imitate $V$-trough-like behaviour. This, along with the lower height profile are the two primary arguments for adoption of such truncated CPCs for use in BIPVs.

In comparing the $50 \mathrm{~mm} \mathrm{CPC}$ and $22^{\circ}$ TWA V-trough it should be noted that the CPC has $C_{\text {opt }}=2.7 \mathrm{vs}$. V-trough of 2.5 at AoI of $0^{\circ}$. The optical concentration ratio of CPC remains constant up to its acceptance half angle of $14.47^{\circ}$ while that for the V-tough concentrator dropping gradually to 1.8 . At light $\mathrm{AoI}=14.47^{\circ}$, the $\mathrm{CPC}$ cliffdrops sharply to $C_{o p t}=1.5$ (vs. 1.8 for V-trough). Beyond light AoI $=14.47^{\circ}$, the CPC and V-trough both show gradual drops in performance, with $\mathrm{V}$-trough having a steeper decline. Due to this steeper decline, the CPC catches in performance with the V-trough at $29^{\circ} \mathrm{AoI}\left(C_{o p t} \sim 1.04\right)$. Beyond $\mathrm{Aol}>29^{\circ}$, the CPC again overtakes the $\mathrm{V}$-trough in performance. Overall, even when considering up to $30^{\circ}$ AoI, for the peak 4-h period, the CPC has 9.4\% performance improvement over the V-trough concentrator. If larger AoI are considered, the $50 \mathrm{~mm} \mathrm{CPC}$ will further its gains; even at $\mathrm{AoI}=45^{\circ}$, the CPC can be seen as still accepting light as shown in Fig. 11.

Fig. 12 and Fig. 13 show the local flux concentration distribution along the width of the absorber (PV cell surface) at AoI of $0^{\circ}$ and $10^{\circ}$ for the concentrators. At AoI of $0^{\circ}$, the V-trough (green line) had a perfectly even distribution along the absorber width and the CPC systems had peaks near the edges of the absorber and bigger peaks mirrored at $10 \mathrm{~mm}$ and $15 \mathrm{~mm}$ positions. The causes of these peaks are discussed later in Fig. 14 and Fig. 15. As the AoI increases, the peaks become asymmetrical and shift in the opposite direction of the incoming light. Fig. 13 shows these shifts. The V-trough was still more uniform in terms of flux distribution at the absorber surface but had two distinct regions of acceptance, high local flux concentration over $0-13 \mathrm{~mm}$ and lower over $13-25 \mathrm{~mm}$ widths. This pattern continued as AoI was increased.

The central peaks shown in Fig. 12 occurred due to the focal 


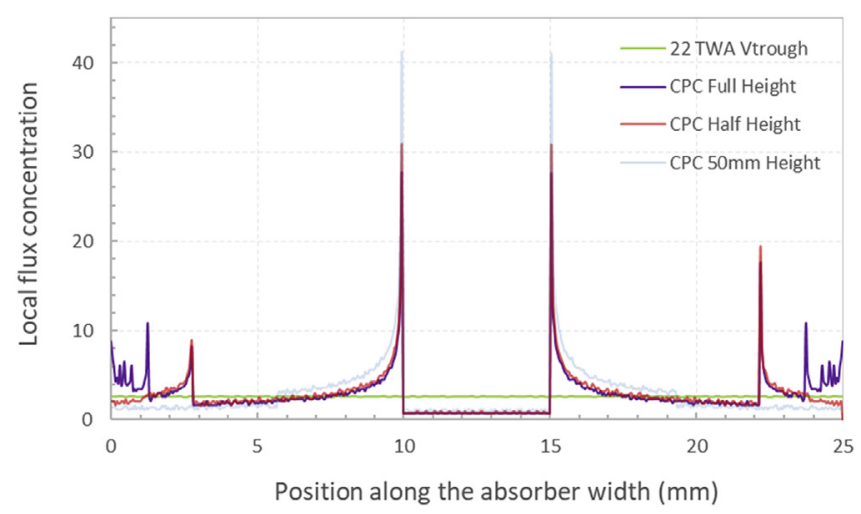

Fig. 12. Flux concentration distribution of $22^{\circ}$ TWA V-trough and $\mathrm{CPC}$ at $\mathrm{AoI}=0^{\circ}$.

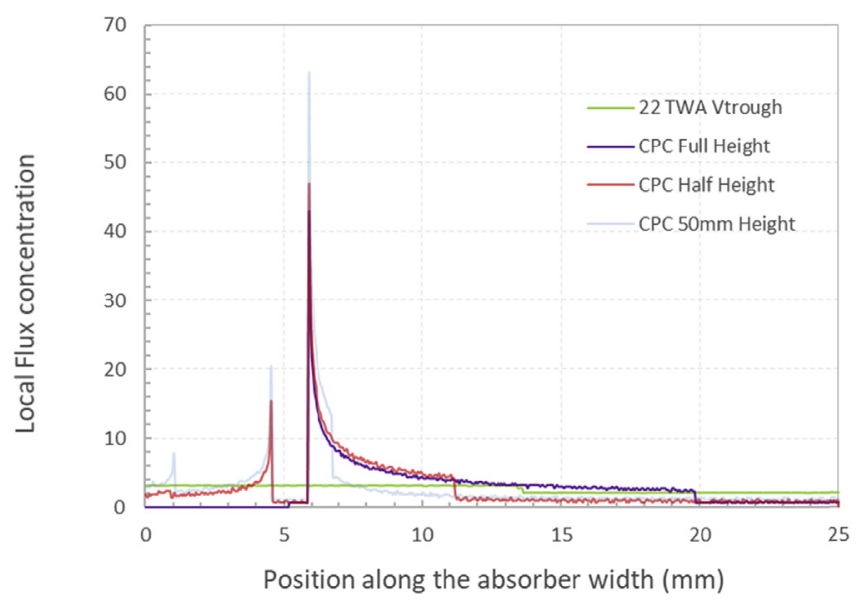

Fig. 13. Flux concentration distribution of $\mathrm{V}$-trough and $\mathrm{CPC}$ at $\mathrm{AoI}=10^{\circ}$.

region of the parabolic reflectors. This is the area the majority of the light rays hitting the reflectors surface (shown in Fig. 14). The

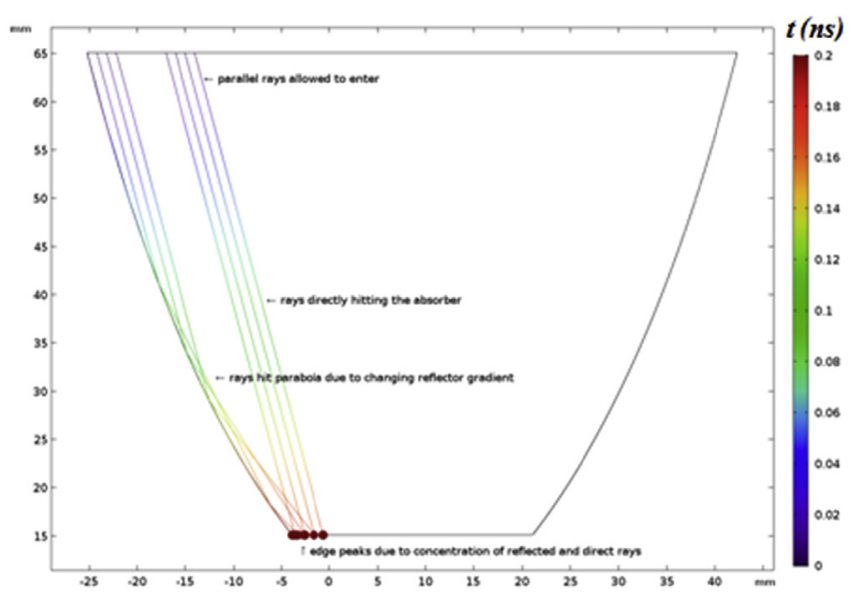

Fig. 15. Ray trace diagram subset demonstrating effect of parabolic curve and truncation on ray acceptance (example shown: $50 \mathrm{~mm} \mathrm{CPC}$ at $\mathrm{AoI}=10^{\circ}$ ).

location of the peaks changes for other values of AoI. The smaller peaks near the edges, shown in Fig. 12, are understood to be caused by overlapping rays entering the CPC at the top which are reflected due to the changing gradient of the parabola. These locations receiving the reflected and directly incident rays exhibited increased local flux concentration distribution. The causes of these peaks are presented in Figs. 14 and 15 with rays coloured based on time. As the Aol increases above $0^{\circ}$, the peaks become asymmetrical and shift in the opposite direction of the incoming light. Fig. 13 shows the shifts of the peaks to the left, due to light incidence on the $\mathrm{CPC}$ at $\mathrm{AoI}=10^{\circ}$ from the left towards the right (Fig. 15).

\section{Experimental studies}

An experimental programme was undertaken to validate the results of computational models described above. CPC and Vtrough concentrators were designed in CAD (SolidWorks) software with cross sections shown in Fig. 16. High-Density Polyurethane

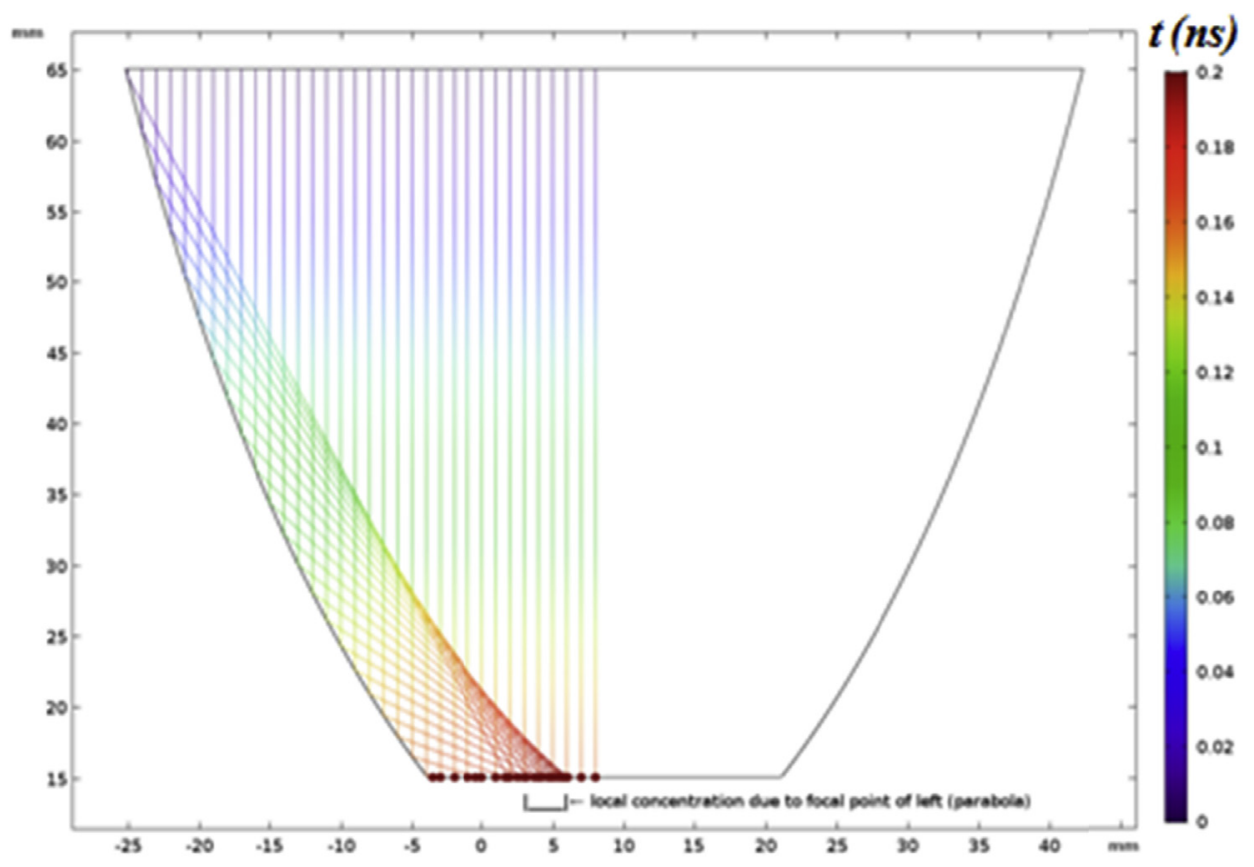

Fig. 14. Central flux concentration occurring due to focal regions of the reflector parabolas (example shown: $50 \mathrm{~mm} \mathrm{CPC}$ at $\mathrm{AoI}=0^{\circ}$ ). 


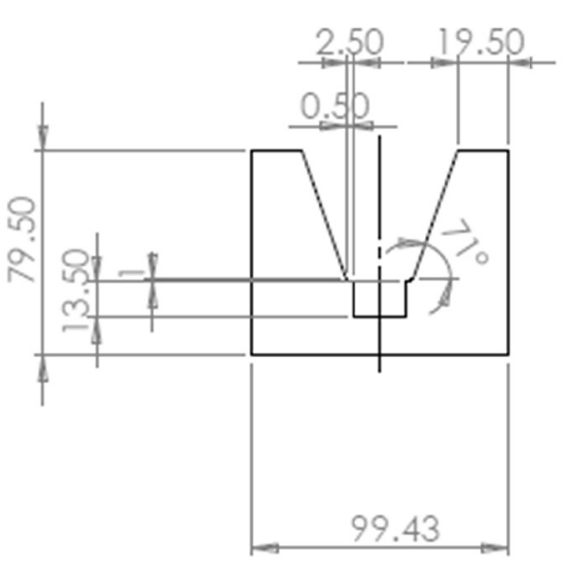

(a)

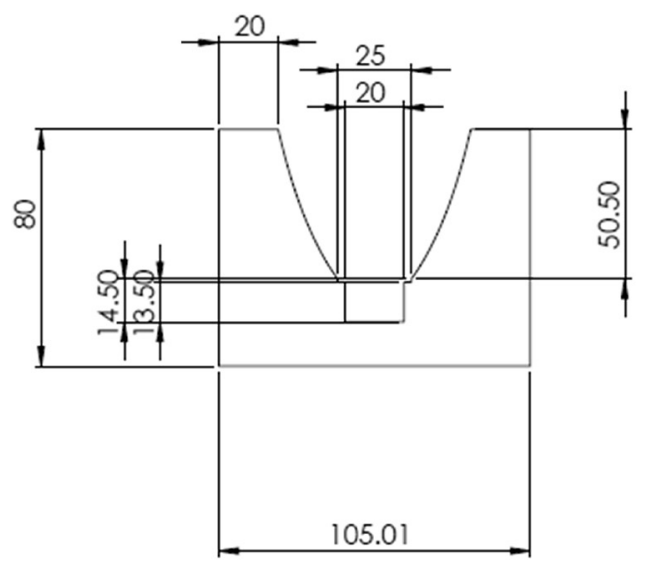

(b)

Fig. 16. Schematic drawings of (a) V-trough and (b) CPC (all dimensions in mm).

Model Board, commonly referred to as Uriel, was employed as the substrate material and profile substrates were manufactured using $\mathrm{CNC}$ milling machine. Uriel is thermally stable up to $130^{\circ} \mathrm{C}$, and further beyond with small losses in tensile strength. Particular attention was paid during cutting the CPC parabolas by adopting small step sizes during milling the troughs.

The PV cells obtained from BISOL [29] were cooled by passing water through a copper pipe welded to a copper plate housing the solar cells. The copper plate also helped in enhancing heat exchange between the PV cells and the coolant. Therefore, a $1 \mathrm{~mm}$ deep groove was provided in both the CPC and V-trough concentrators (Fig. 16) to accommodate the copper plate, the thermal paste and electrical insulation. The absorber area for both concentrators was $25 \mathrm{~mm} \times 250 \mathrm{~mm}$ with solar cells purchased in standard $156 \mathrm{~mm} \times 156 \mathrm{~mm}$ blocks. The PV cells were cut to $25 \mathrm{~mm} \times 125 \mathrm{~mm}$ and two units connected in series to match with the absorber area. Since the Si-solar cells used are comprised of silicon wafers with aluminium back plating, the cutting was done using low power $\mathrm{CO}_{2}$ laser machine to etch the front of the silicon and snap along the lines. To electrically insulate the solar cells from the copper plate while allowing the heat transfer, Mica electrical insulating film was sandwiched between the two. Mica sheets (MIC-20) purchased from RS Components \& Controls Ltd rated at heat resistant up to temperature of $500^{\circ} \mathrm{C}$. Thermal paste was applied to both sides of the Mica sheet to ensure good physical contact for transfer of heat from solar cell to copper tube. The final assembled concentrator system is shown in Fig. 17.

Alanod Miro-Silver 2 4200AG with $>98 \%$ total reflection [30] was used as the reflector surface in both concentrators. The MiroSilver 2 sheet was glued to the concentrator substrate at respective reflector walls. The reflector sheets for CPC concentrator were pre-shaped using a bending machine prior to attachment to ensure they took the shape of the parabola prior to the adhesive's setting. The final concentrators are shown in Fig. 18.

The schematic presented in Fig. 19 shows the connectivity of all components in the experimental test unit developed during this research. The pyranometer attached measures total solar radiation, the second yellow cable running from the Pico data logger connects to the shaded pyranometer to measure diffuse solar radiation. A Keithley 2401 SMU acquisition system was employed to measure I$\mathrm{V}$ characteristics of the solar cells.

Tables 2-4 provide the technical specifications of the two pyranometers and the Pico TC-08 data logger used.

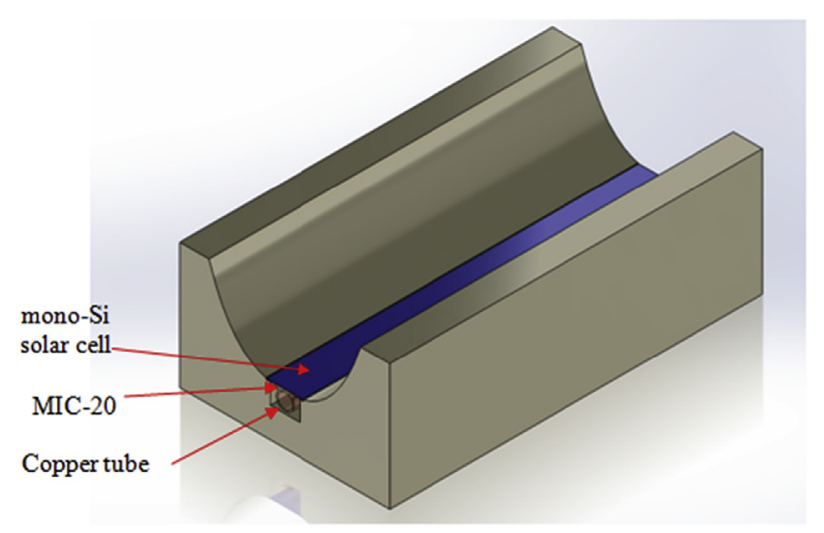

Fig. 17. Final Assembly of the concentrator system.

\section{Comparison of experimental and modelling results}

Ponce-Alcántara et al. [31] performed an experimental study of the effect of temperature variation with the performance of silicon solar cells. They presented the effect of temperature as a temperature coefficient of maximum power point $\left(\mathrm{CTP}_{\mathrm{mpp}}\right)$ with the power output defined as follows:

$$
P_{m p p}=P_{m p p}\left(25^{\circ} \mathrm{C}\right) \cdot\left[1+C T P_{m p p}\left(T-25^{\circ} \mathrm{C}\right)\right]
$$

The temperature coefficient for c-Si was reported at $~-0.45 \%$ / ${ }^{\circ} \mathrm{C}$. Experimental studies were carried out considering the effects of cooling on LCPV performance. The readings were taken as close to solar noon (i.e. $0^{\circ}$ angle of incidence) as possible. Table 5 presents the results of the CPC concentrator with the cooling pipe turned on and off. Solar noon on the 20th September 2017 occurred at 12:53 p.m. local time.

Results show the non-cooled CPC operates at $-12.44 \%$ power output (W) due to a temperature rise of $30.9^{\circ} \mathrm{C}$. This translates into a temperature coefficient of $-0.40 \% /{ }^{\circ} \mathrm{C}$. Fig. 20 presents the I-V (and $\mathrm{P}-\mathrm{V}$ ) measurements for cooled and non-cooled CPC concentrator.

Fig. 21 shows the experimental direct and diffuse solar radiation data collected on the 20th Sept 2017, presented due to the clear skies on the day and good solar irradiance. Orange (diffuse) data was collected with a shaded pyranometer, blue (direct) data was total irradiance taken with pyranometer on plane of concentrator 


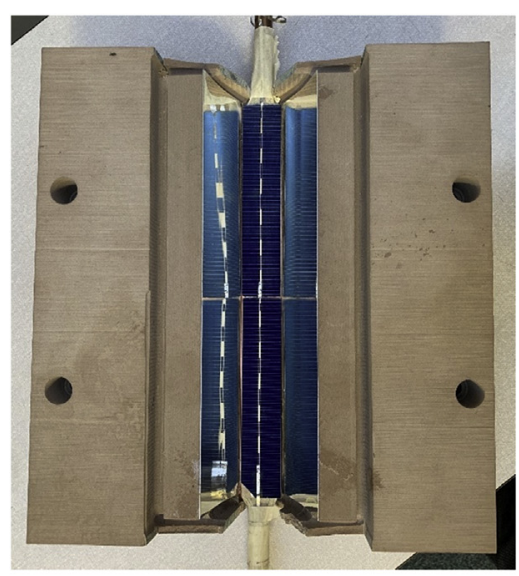

(a) CPC final setup

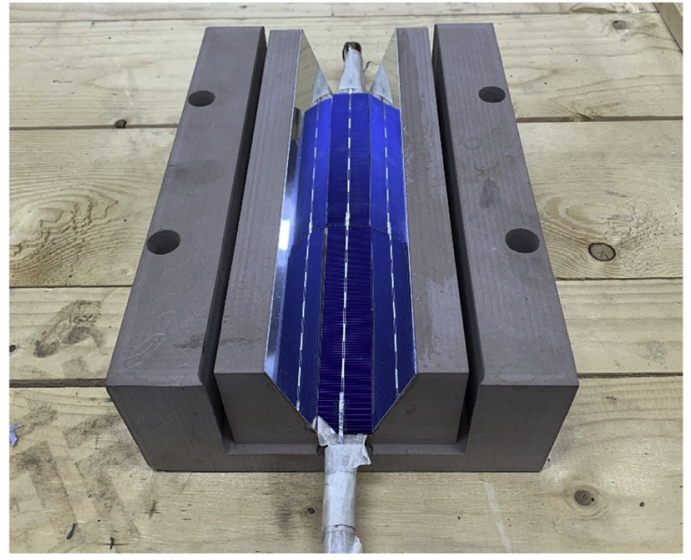

(b) V-trough final setup

Fig. 18. Manufactured concentrators with solar cell, copper pipe, heat transfer copper plate and bus-bar junction: (a) CPC and (b) V-trough.

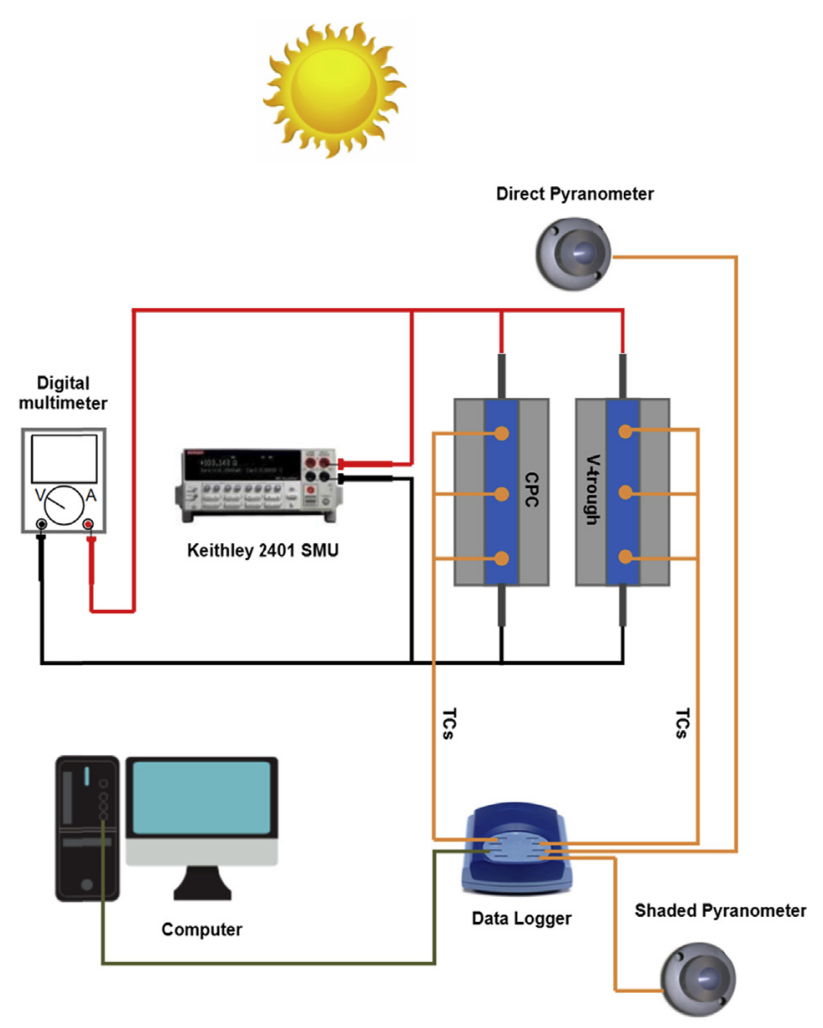

Fig. 19. Experimental setup employed to test the concentrators under realistic ambient conditions.

Table 2

Pyranometer technical specifications.

\begin{tabular}{ll}
\hline SP Lite2 Pyranometer & \\
\hline Spectral range (overall) & $400-1100 \mathrm{~nm}$ \\
Sensitivity & $60-100 \mu \mathrm{V} / \mathrm{W} / \mathrm{m}^{2}$ \\
Response time SP Lite2 (95\%) & $<500 \mathrm{~ns}$ \\
Directional response (up to $80^{\circ}$ with $1000 \mathrm{~W} / \mathrm{m}^{2}$ beam) & $<10 \mathrm{~W} / \mathrm{m}^{2}$ \\
Temperature response & $<-0.15 \%$ \\
Operational temperature range & $-40{ }^{\circ} \mathrm{C}$ to $+80{ }^{\circ} \mathrm{C}$ \\
Maximum solar irradiance & $2000 \mathrm{~W} / \mathrm{m}^{2}$ \\
Field of view & $180^{\circ}$ \\
\hline
\end{tabular}

Table 3

Pico TC-08 data logger technical specifications.

\begin{tabular}{ll}
\hline Number of channels & 8 \\
Conversion time & $100 \mathrm{~ms}$ \\
Temperature accuracy & Sum of $\pm 0.2 \%$ of reading and $\pm 0.5 \mathrm{deg} C$ \\
Voltage Accuracy & Sum of $\pm 0.2 \%$ of reading and $\pm 10 \mathrm{uV}$ \\
Resolution (Noise free) & $16.25 \mathrm{bits}$ \\
Operating temperature & $0-50 \mathrm{deg} \mathrm{C}$ \\
\hline
\end{tabular}

Table 4

TC-08 Pico data logger thermocouple resolution.

\begin{tabular}{llll}
\hline Thermocouple type & Overall range ${ }^{\circ} \mathrm{C}$ & $0.1{ }^{\circ} \mathrm{C}$ resolution & $0.025{ }^{\circ} \mathrm{C}$ resolution \\
\hline B & 20 to 1820 & 150 to 1820 & 600 to 1820 \\
E & -270 to 910 & -270 to 910 & -260 to 910 \\
J & -210 to 1200 & -210 to 1200 & -210 to 1200 \\
K & -270 to 1370 & -270 to 1370 & -250 to 1370 \\
N & -270 to 1300 & -260 to 1300 & -230 to 1300 \\
R & -50 to 1760 & -50 to 1760 & 20 to 1760 \\
S & -50 to 1760 & -50 to 1760 & 20 to 1760 \\
T & -270 to 400 & -270 to 400 & -250 to 400 \\
\hline
\end{tabular}

with diffuse radiation deducted.

Fig. 22 to Fig. 24 present the experimental power output of the CPC, flat-plate (non-concentrator) and V-trough modules. It can be seen that the power output of the flat plate solar cell is significantly lower. Conversely, the performance drop due to increased angle of incidence (solar time) is less and the power output of the flat plate solar cell tracks the solar irradiance throughout the day (see Fig. 23).

The measured power output of developed CPV concentrators, CPC and V-trough, and that calculated from ray-trace modelling are compared in Fig. 25. The ray tracing model output was converted to power by considering the system's real power conversion efficiency and optical efficiency based on:

Power $(W)=\tau_{g} \times R_{\text {spec }} \times \eta$

Where $\tau_{g}$ is the glass transmittance, set to $100 \%$ for comparison to experiments, $R_{\text {spec }}$ is the specular reflectance losses of the Alanod reflector sheet (92\%) and $\eta$ is the solar cell power conversion efficiency set at $15 \%$ based on average measurements.

A good correlation between the experimental measurements and model power output results was found. The experimental CPC 
Table 5

CPC under cooled and non-cooled conditions 20th Sept 2017.

\begin{tabular}{|c|c|c|c|c|c|c|c|c|c|}
\hline TIME (LOCAL) & & CONC & $\operatorname{TEMP}\left({ }^{\circ} \mathrm{C}\right)$ & $\mathrm{I}_{\mathrm{SC}}$ & $\mathrm{V}_{\mathrm{OC}}$ & $\mathrm{P}(\mathrm{W})$ & DIRECT + DIFFUSE $\left(\boldsymbol{W} / \boldsymbol{m}^{2}\right)$ & DIFFUSE $\left(\boldsymbol{W} / \boldsymbol{m}^{2}\right)$ & DIFFUSE (\%) \\
\hline $12: 45$ & Cooled & $\mathrm{CPC}$ & 32.32 & 1.61 & 1.2 & 1.932 & 1102.61 & 104.31 & $9.5 \%$ \\
\hline $12: 45$ & Heated & $\mathrm{CPC}$ & 63.22 & 1.42 & 1.2 & 1.704 & 1102.61 & 104.31 & $9.5 \%$ \\
\hline
\end{tabular}

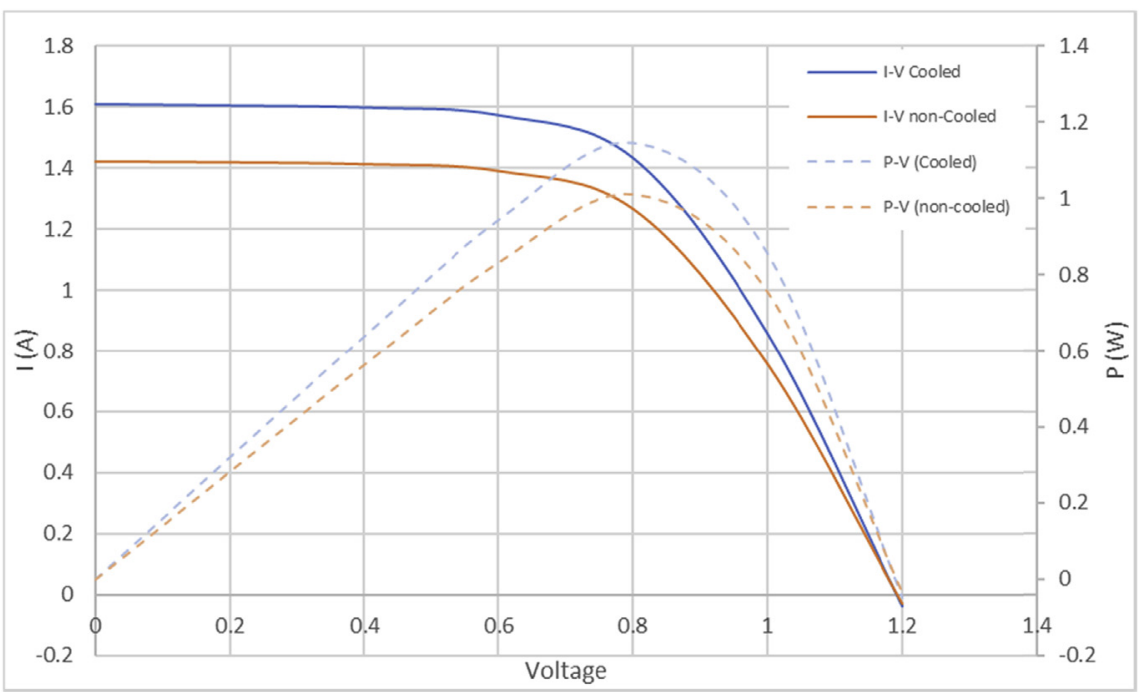

Fig. 20. $\mathrm{I}-\mathrm{V}$ and $\mathrm{P}-\mathrm{V}$ curves of $50 \mathrm{~mm} \mathrm{CPC}$ with and without active cooling.

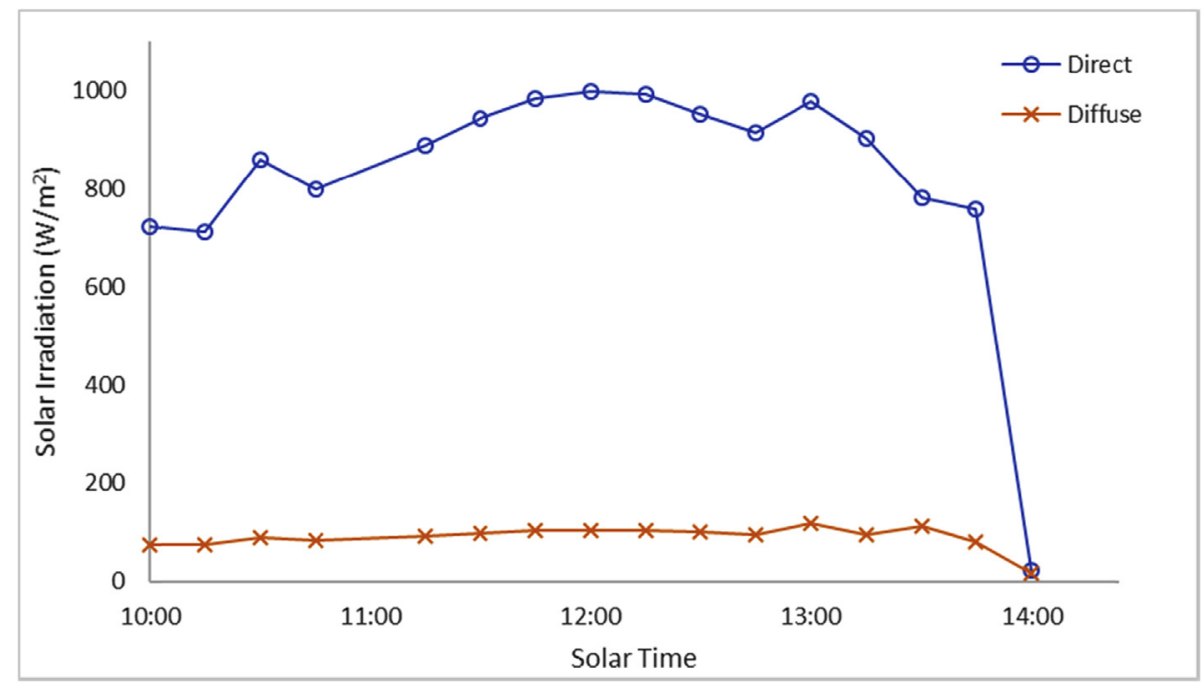

Fig. 21. Direct and diffuse solar radiation 20th Sept 2017.

measurements showed constant power output for AoI $\sim \pm 15^{\circ}$, in line with model results. The V-trough measurements showed a near linear drop with respect to light Aol changes in both directions. This was again in good corroboration with the model predictions.

On average the CPC showed a $2.4 \%$ higher power output than Vtrough. However, this was lower than predicted by the COMLSOL Multiphysics ray tracing models. The most likely cause of the discrepancy is the increased energy flux non-uniformity of the CPC concentrators which resulted in reduction of power output of the
CPV system.

Similar studies were carried out by Singh et al. [32]. They showed that for the V-trough and CPC systems with the same geometrical concentration ratio, the $\mathrm{V}$-trough concentrator had an electrical power output up to $17.2 \%$ higher than the CPC system at a specific tilt angle of $30^{\circ}$ and the $\mathrm{V}$-trough had a consistently higher receiver plate temperature. Redpath et al. [33] also showed that CPC integrated combi photovoltaic-thermal (PVT) had a lower thermal efficiency than flat plate PVT with a heat removal factor of 0.488 compared to 0.638 of the later. 


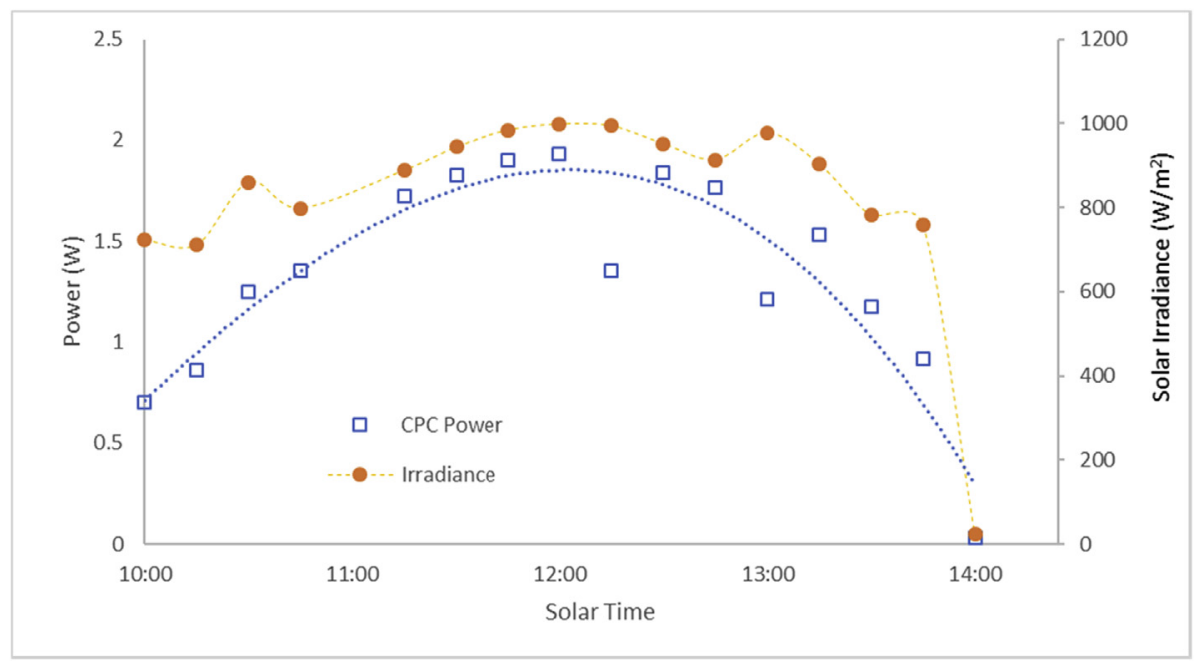

Fig. 22. Power output and solar irradiance for CPC for period 10:00 to 14:00 solar time.

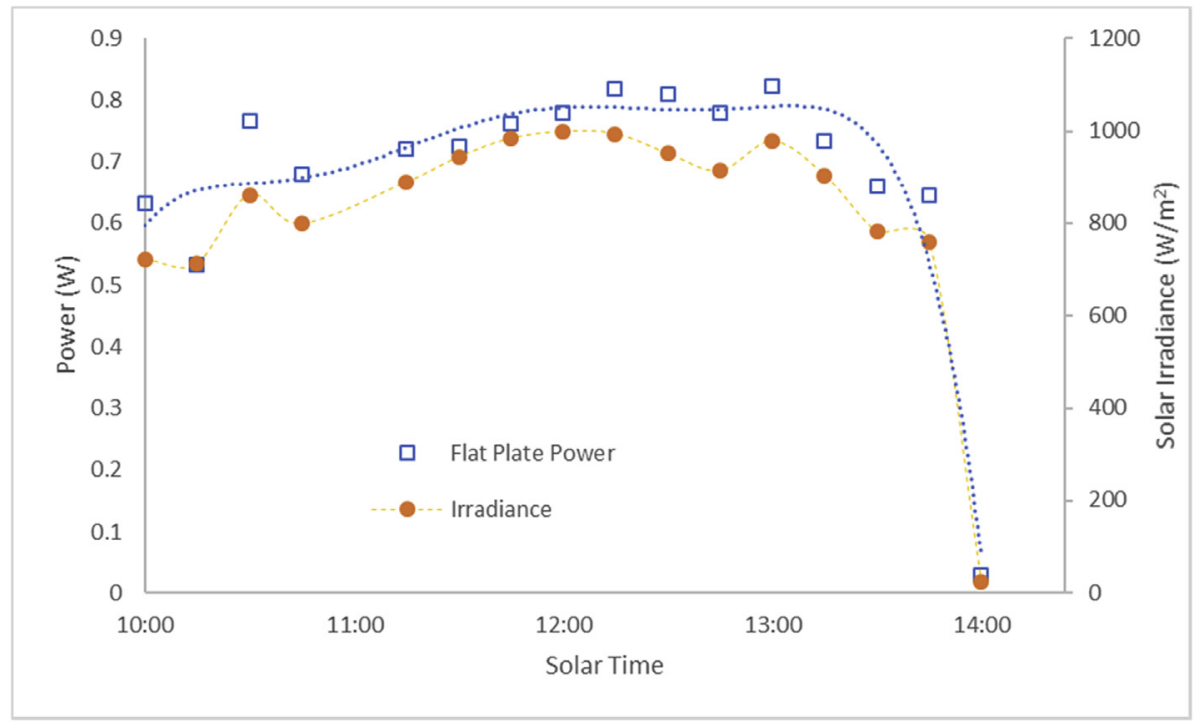

Fig. 23. Power output and solar irradiance for flat plate solar cell for period 10:00 to 14:00 solar time.

However, the results from the current research showed a better performance of CPC rather than V-trough. This could be down to geometric optimisations performed by COMSOL Multiphysics leading to a better prototype design. Another difference is that the CPC fabricated in this study was smaller in scale for BIPV integration, e.g. the absorber width was $25 \mathrm{~mm}$ compared to $125 \mathrm{~mm}$ used in Singh et al. [32].

\section{Conclusion}

The CPC and V-trough concentrators investigated in this study showed good robustness in their performance despite not tracking the sun. This makes them best candidates for BIPV/BAPV applications where such devices can be used as fixed concentrating generators since installing operating and maintaining tracking CPV systems is expensive and complex. Additionally, the low concentrating designs investigated can also harness a proportion of the incident diffuse radiation; a feature which is of particular interest for locations such as the UK and other northern maritime climatic zones.
A $50 \mathrm{~mm}$ truncated-CPC and $50 \mathrm{~mm}$ V-trough were contrasted and compared. It is shown that a drop in the performance of both concentrators occurs at increased angles of incidence (AoI). The drop beings at $14.47^{\circ}$ for CPC and immediately for V-trough; however, the V-trough concentrator showed lower losses as incidence angle increased compared to non-truncated CPC systems.

The truncated CPC design proposed in this study furthers the advantages by improving acceptance from $\pm 14.5^{\circ}$ to beyond $\pm 45^{\circ}$, although with diminishing returns. This comes at the cost of a reduction of concentration ratio, although the height profile reduction of $80 \%$ is a necessity for BIPV integration, for example, to fit CPV units within window gap or on vertical walls.

The results showed and quantified the increase in angle of acceptance, reductions in height profile and V-trough-like characteristics past the original CPC design acceptance angles, with consequence in reducing material consumption for the manufacture of CPC and therefore reduction in the cost of the system.

For ray tracing analysis a variety of direct and iterative solvers were tested, and the generalized minimal residual method was used for the analysis of concentrators. A drop of performance was 


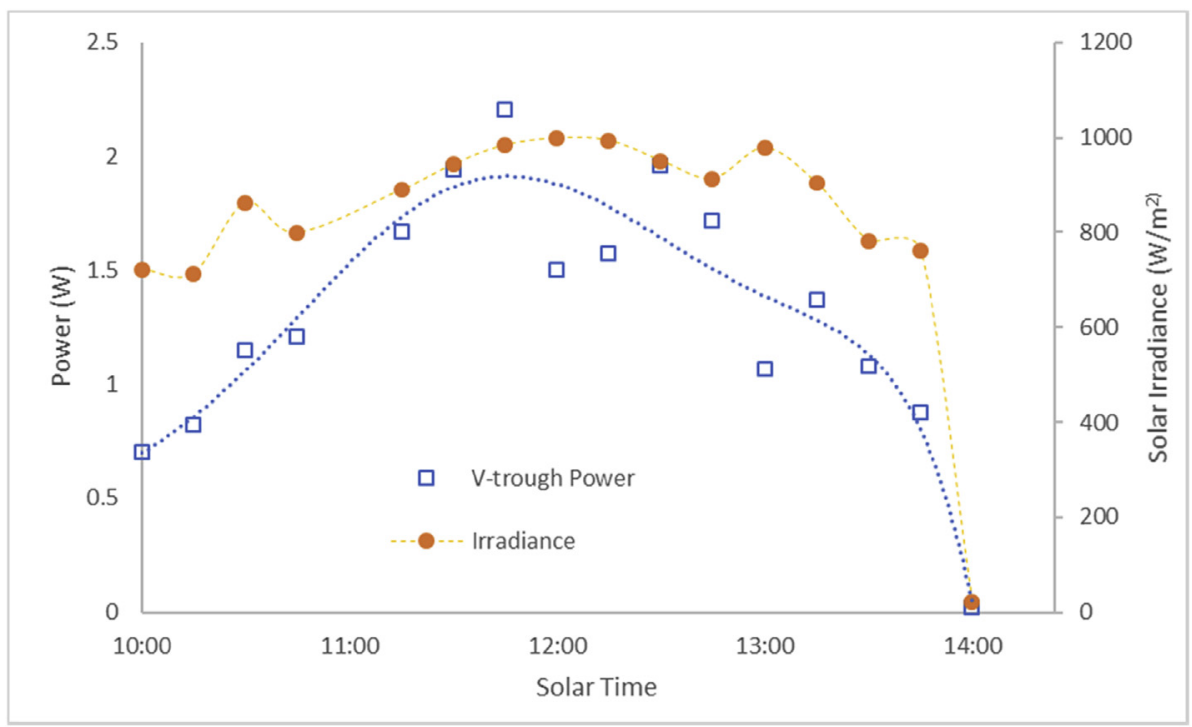

Fig. 24. Power output and solar irradiance for V-trough concentrator for period 10:00 to 14:00 solar time.

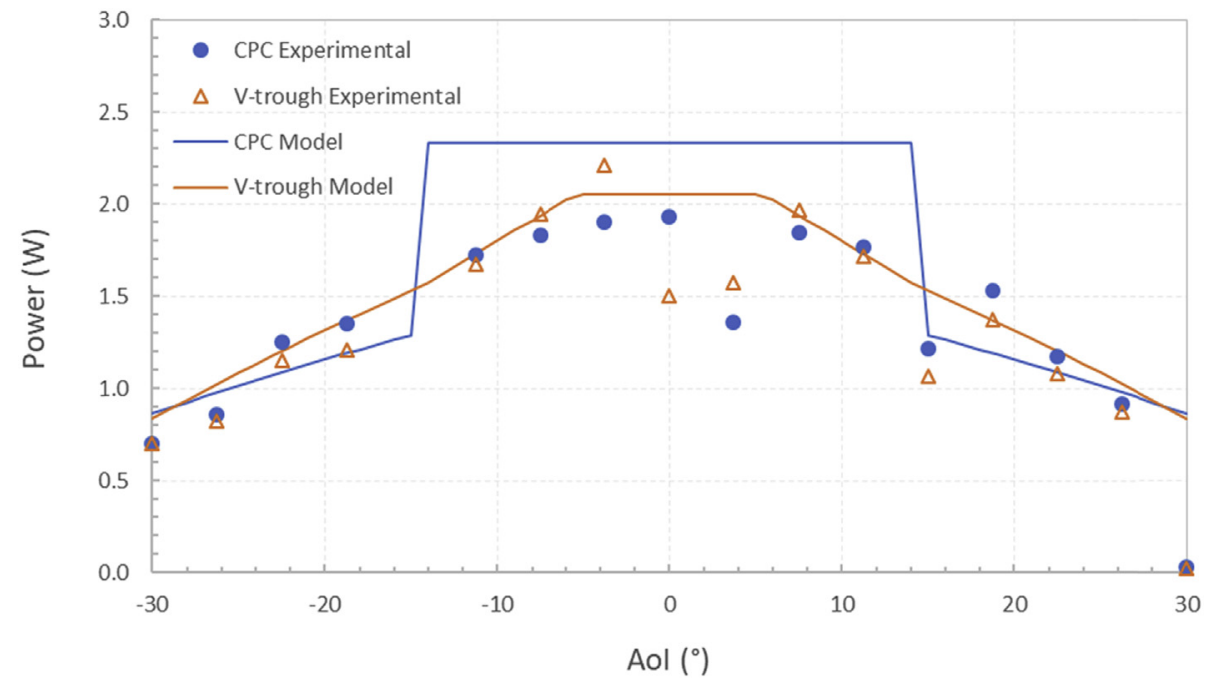

Fig. 25. Experimental and modelling power output from CPC and V-trough concentrators over various light angles of incidence.

observed for both concentrators at increased AoI; however, Vtrough showed a better ability to dampen the loss as incidence angle increased. In terms of concentration ratio, a truncated CPC at equal height showed an optical concentration ratio of 2.70 whilst $V$ trough hovered around 2.38 resulting in a net performance increase of $13 \%$ for CPC adoption. Results showed V-trough having lower concentration ratios but better performance at high angles of incidence compared to CPCs. Truncated CPCs showed equal optical efficiency to their full height parents but a lower concentration ratio due to a reduction in inlet aperture size.

The modelled $50 \mathrm{~mm}$ CPC concentrator particularly designed for BIPV showed a greater overall concentrating performance, with significantly improved concentration for AoI up to the half acceptance angle, a small loss compared to the V-trough for Aol between half acceptance angle to $29^{\circ}$, and again an improvement over the Vtrough from for Aol $>30^{\circ}$. All truncated CPCs also show V-troughlike behaviour past their acceptance angles, making them suitable for BIPV incorporation. On the other hand, the V-trough concentrator showed better uniformity of flux distribution, this was especially pronounced at $0^{\circ}$ Aol with flux distribution being perfectly uniform.

The experimental investigation was carried out on two concentrators, a CPC design and a V-trough one and for both systems the optical and energy conversion characteristics were experimentally measured. The analysis of the experimental power output data showed good correlation with ray tracing simulations, showing similar behaviour with changing AoI. CPC was found to have an overall $2.4 \%$ higher power output compared to V-trough concentrator. Although this was lower than the difference predicted by modelling analysis, the discrepancy was put down to the non-uniformity of the concentrated light on the CPC absorber plane and differences in contour and surface characteristics between the ideal and the manufactured parabolic reflectors.

\section{Acknowledgement}

First author thanks UK's Engineering and Physical Sciences Research Council's Doctoral Training Partnership programme to 
fund his PhD study, which made this research possible.

\section{Appendix A. Supplementary data}

Supplementary data to this article can be found online at https://doi.org/10.1016/j.renene.2019.02.121.

\section{References}

[1] REN21, Renewables 2018 Global Status Report, 2018. Available: http://www ren21.net/wp-content/uploads/2018/06/17-8652_GSR2018_FullReport_web_ final_.pdf. (Accessed 9 December 2018).

[2] M. Wiesenfarth, S.P. Philipps, A.W. Bett, K. Horowitz, S. Kurtz, Current Status of Concentrator Photovoltaic (CPV) Technology, Fraunhofer Institute for Solar Energy Systems ISE in Freiburg and NREL, Germany, April 2017. Version 1.3.

[3] S. Madala, R.F. Boehm, A review of nonimaging solar concentrators for stationary and passive tracking applications, Renew. Sustain. Energy Rev. 71 (2017) 309-322.

[4] K. Shanks, S. Senthilarasu, T.K. Mallick, Optics for concentrating photovoltaics: trends, limits and opportunities for materials and design, Renew. Sustain. Energy Rev. 60 (2016) 394-407.

[5] A.D. Vos, Detailed balance limit of the efficiency of tandem solar cells, J. Phys. D Appl. Phys. 13 (5) (1980) 839.

[6] H. Hinterberger, R. Winston, Efficient light coupler for threshold Cerenkov counters, Rev. Sci. Instrum. 37 (1966a) 1094-1095.

[7] S. Kurtz, D. Myers, W.E. McMahon, J. Geisz, M. Steiner, A comparison of theoretical efficiencies of multi-junction concentrator solar cells, Prog. Photovoltaics Res. Appl. 16 (6) (2008) 537-546.

[8] F. Dimroth, Four-junction wafer bonded concentrator solar cells, IEEE J. Photovolt. 6 (2016) 343-349.

[9] M. Adsten, B. Hellstrom, Measurement of radiation distribution on the absorber in an asymmetric CPC collector, Sol. Energy 76 (1-3) (2004) 199-206.

[10] H. Hatwaambo, H. Hakansson, Angular characterization of low concentrating PV-CPC using low-cost reflectors, Sol. Energy Mater. Sol. Cell. 92 (11) (2008) 1347-1351.

[11] D.I. Paul, M. Smyth, A. Zacharopoulos, J. Mondol, The design, fabrication and indoor experimental characterisation of an isolated cell photovoltaic module Sol. Energy 88 (2013) 1-12.

[12] W.T. Welford, R. Winston, The Optics of Non-imaging Concentrators, Academic Press, New York, NY, USA, 1978.

[13] W.A.M. Al-Shohani, R.K. Al-Dadah, S. Mahmoud, A. Algareu, Optimum design of V-trough concentrator for photovoltaic applications, Sol. Energy 140 (2016) 241-254.

[14] C.S. Sangani, C.S. Solanki, Experimental evaluation of V-trough (2 suns) PV concentrator system using commercial PV modules, Sol. Energy Mater. Sol. Cells 91 (2007) 453-459.

[15] T.K. Mallick, P.C. Eames, T. Hyde, B. Norton, The design and experimental characterisation of an asymmetric compound parabolic photovoltaic concentrator for building facade integration in the UK, Sol. Energy 77 (3) (2004) 319-327.

[16] T.K. Mallick, P.C. Eames, B. Norton, Power losses in an asymmetric compound parabolic photovoltaic concentrator, Sol. Energy Mater. Sol. Cell. 91 (12) (2007) 1137-1146.

[17] A.K. Shukla, K. Sudhakar, P. Baredar, Recent advancement in BIPV product technologies: a review, Energy Build. 140 (2017) 188-195.

[18] X. Wu, Y. Liu, J. Xu, W. Lei, J. Lin, Monitoring the performance of the building attached photovoltaic (BAPV) system in Shanghai, Energy Build. 88 (2015) $174-182$.

[19] N.M. Kumar, K. Sudhakar, M. Samykano, Performance comparison of BAPV and BIPV systems with c-Si, CIS and CdTe photovoltaic technologies under tropical weather conditions, Case Stud. Therm. Eng. 13 (2019), 100374.

[20] B. Norton, P.C. Eames, T.K. Mallick, M.J. Huang, S.J. Mc Cormack, J.D. Mondol, Y.G. Yohanis, Enhancing the performance of building integrated photovoltaics, Sol. Energy 85 (8) (2011) 1629-1664.

[21] A. Rabl, Comparison of solar concentrators, Sol. Energy 18 (2) (1973) 93-111.

[22] A. Rabl, Optical and thermal properties of compound parabolic concentrators, Sol. Energy 18 (6) (1976) 497-511.

[23] H. Hinterberger, R. Winston, Gas Cerenkov counter with optimized lightcollecting efficiency, Proc. Int. Instrum. High Energy Phys. (1966b) 205-206.

[24] V. Baranov, A paper in Russian that introduces certain properties of CPCs, Opt. Mekh. Prom. 6 (1965a) 1-5.

[25] V. Baranov, G. Melnikov, Study of the illumination characteristics of hollow focons, Sov. J. Opt. Technol. (1966) 408-411.

[26] V. Baranov, Eng transL: Parabolotoroidal mirrors as elements of solar energy concentrators, Appl. Sol. Energy 2 (1966) 9-12. Geliotekhnika, vol. 2, pp. $11-14$.

[27] R. Winston, Principles of solar concentrators of a novel design, Sol. Energy 16 (1974) 89-95.

[28] M. Tiana, Y. Su, H. Zheng, G. Pei, G. Li, S. Riffat, A review on the recent research progress in the compound parabolic concentrator (CPC) for solar energy applications, Renew. Sustain. Energy Rev. 82 (Part 1) (2018) 1272-1296.

[29] BISOL, BISOL Datasheets, Available: http://www.bisol.com/images/ Datasheets/EN/BISOL\%20Product\%20Specification\%20BMO_EN.pdf. (Accessed 12 February 2018).

[30] Alanod, MIRO-SILVER® Catalogue, 2017. Available: https://www.alanod.com/ wp-content/uploads/2017/02/MIRO_SILVER_PD_8s_FINAL_D_E_11_14.pdf. (Accessed 10 February 2018)

[31] S. Ponce-Alcántara, J. Patrick Connolly, G. Sánchez, J. Manuel Míguez, V. Hoffmann, R. Ordás, A statistical analysis of the temperature coefficients of industrial silicon solar cells, in: 4th International Conference on Silicon Photovoltaics, SiliconPV 2014, vol. 55, 2014, pp. 578-588.

[32] H. Singh, M. Sabry, D. Redpath, Experimental investigations into low concentrating line axis solar concentrators for CPV applications, Sol. Energy 136 (2016) 421-427.

[33] D.A.G. Redpath, H. Singh, C. Tierney, P. Dalzell, An experimental comparison of two solar photovoltaic thermal (PVT) energy conversion systems for production of heat and power, Energy Power 2 (4) (2012) 46-50. 